\title{
COMPARISON OF THE RADIOACTIVE AND MODIFIED TECHNIQUES FOR MEASUREMENT OF STREAM REAERATION COEFFICIENTS
}

\section{U.S. GEOLOGICAL SURVEY}

\section{WATER-RESOURCES INVESTIGATIONS 78-68}

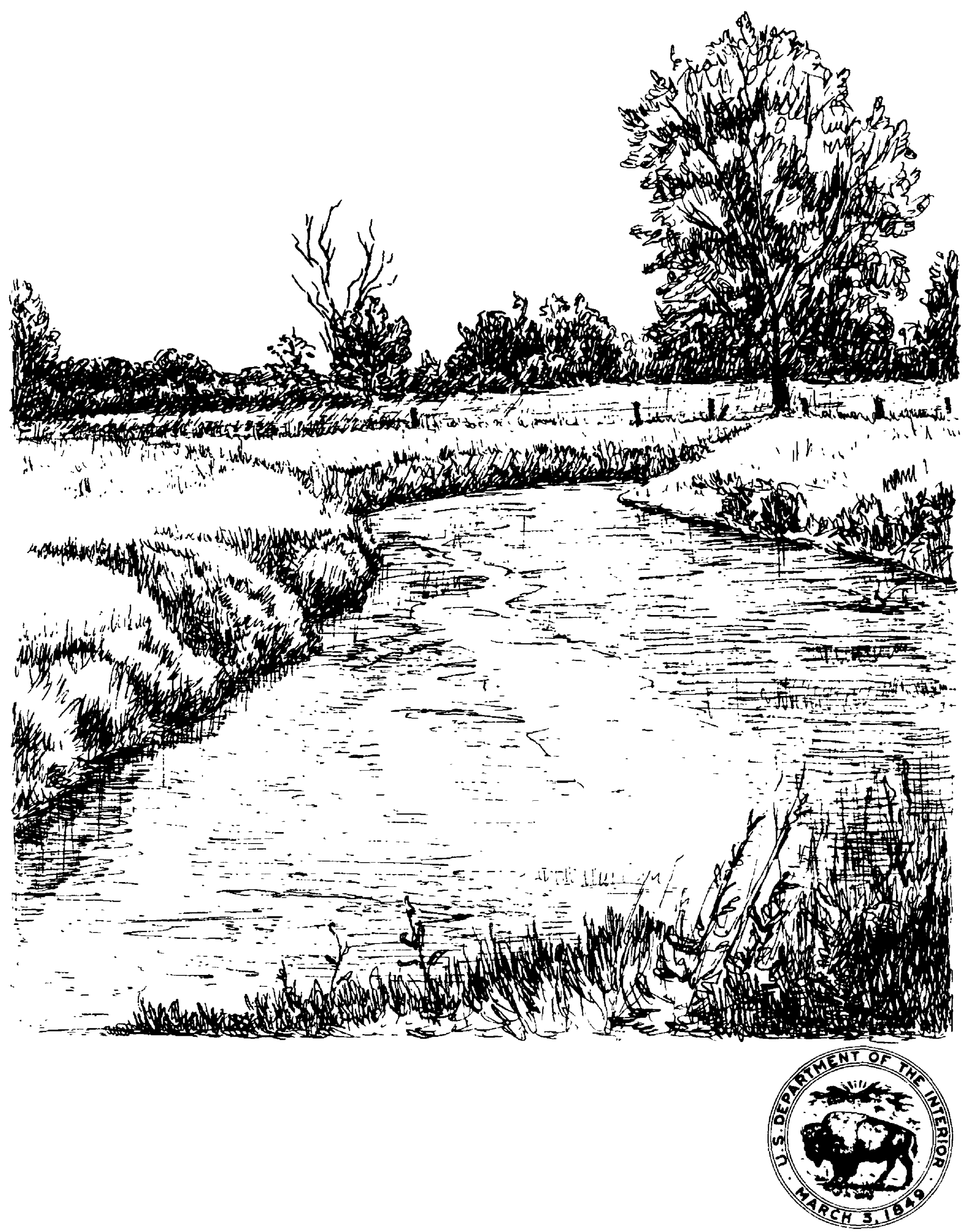




\begin{tabular}{|c|c|c|}
\hline $\begin{array}{l}\text { BIBLIOGRAPHIC DATA } \\
\text { SHEET }\end{array}$ & 1. Report No. & 3. Recipient's Accession No. \\
\hline \multirow{2}{*}{\multicolumn{2}{|c|}{$\begin{array}{l}\text { 4. Title and Subtitle } \\
\text { Comparison of the Radioactive and Modified Techniques for } \\
\text { Measurement of stream Reaeration Coefficients }\end{array}$}} & $\begin{array}{l}\text { 5. Report Date } \\
\text { May } 1978\end{array}$ \\
\hline & & 6. \\
\hline \multicolumn{2}{|c|}{$\begin{array}{l}\text { 7. Aurhot(s) } \\
\text { R. E. Rathbun and R. S. Grant }\end{array}$} & $\begin{array}{l}\text { 8. Performing Organization Rept. } \\
\text { No. USGS/WRI }-78-68\end{array}$ \\
\hline \multirow{2}{*}{\multicolumn{2}{|c|}{$\begin{array}{l}\text { 9. Performing Organization Name and Address } \\
\text { U.S. Geological Survey, Water Resources Division } \\
\text { Gulf Coast Hydroscience Center } \\
\text { National Space Technology Laboratories } \\
\text { NSTL Station, Mississippi } 39529\end{array}$}} & 10. Project/Task/Work Unit No. \\
\hline & & 11. Contract/Gtant No. \\
\hline \multirow{2}{*}{\multicolumn{2}{|c|}{$\begin{array}{l}\text { 12. Sponsoring Organization Name and Address } \\
\text { U.S. Geological Survey, Water Resources Division } \\
\text { Gulf Coast Hydroscience Center } \\
\text { National Space Technology Laboratories } \\
\text { NSTL Station, Mississippi } 39529\end{array}$}} & $\begin{array}{l}\text { 13. Type of Report \& Period } \\
\text { Covered } \\
\text { Final }\end{array}$ \\
\hline & & 14. \\
\hline
\end{tabular}

15. Supplementary Notes

16. Abstracts The radioactive and modified tracer techniques were used to measure the reaeration coefficients of two reaches each of Black Earth Creek and the Madison Effluent Channel near Madison, wis. Coefficients measured with the modified technique were from -8.96 to +3.61 and from +15.7 to +32.2 percent different from the coefficient measured with the radioactive tracer technique on Black Earth creek. The larger coefficients measured with the modified technique on the second reach were attributed to increased wind conditions during the latter part of the modified-technique experiment. Interpretation of the Madison Effluent Channel study was complicated by an unsteady flow condition during the modified-technique experiment which required estimation of the dye loss and the discharge increase. Using these estimated values, the coefficients measured with the modified technique were from +25.3 to +57.9 and from -4.74 to +2.94 percent different from the coefficient measured with the radioactive technique on the Madison Effluent Channel. Results of this study suggest that the modified technique is a promising alternative to the use of radioactive tracers.

17. Key Words and Document Analysis. 17a. Descriptors

*Reaeration, *Tracers, *Radioactive tracers, Measurement, streamflow, oxygenation, Dissolved oxygen, Water pollution

17b. Identifiers/Open-Ended Terms

*Reaeration coefficient, *Non-radioactive tracers, Dye tracing, Wisconsin

17c. COSATI Field/Group

18. Availability Statement

No restriction on distribution.

\begin{tabular}{|l|c|}
$\begin{array}{l}\text { 19. Security Class (This } \\
\text { Report) } \\
\text { UNClASSIFUED }\end{array}$ & $\begin{array}{c}\text { 21. No. of Pages } \\
65\end{array}$ \\
\hline $\begin{array}{c}\text { 20. Security Class (This } \\
\text { Page } \\
\text { UNCLASSIFIED }\end{array}$ & 22. Price \\
\hline
\end{tabular}


COMPARISON OF THE RADIOACTIVE AND MODIFIED TECHNIQUES

FOR MEASUREMENT OF STREAM REAERATION COEFFICIENTS

By R. E. Rathbun and R. S. Grant

U.S. GEOLOGICAL SURVEY

Water-Resources Investigations 78-68

May 1978 
UNITED STATES DEPARTMENT OF THE INTERIOR

CECIL D. ANDRUS, Secretary

GEOLOGICAL SURVEY

H. William Menard, Director

For additional information write to:

U.S. Geological Survey, WRD

Gulf Coast Hydroscience Center

Building 2101

NSTL Station, Mississippi 39529 
CONTENTS

Page

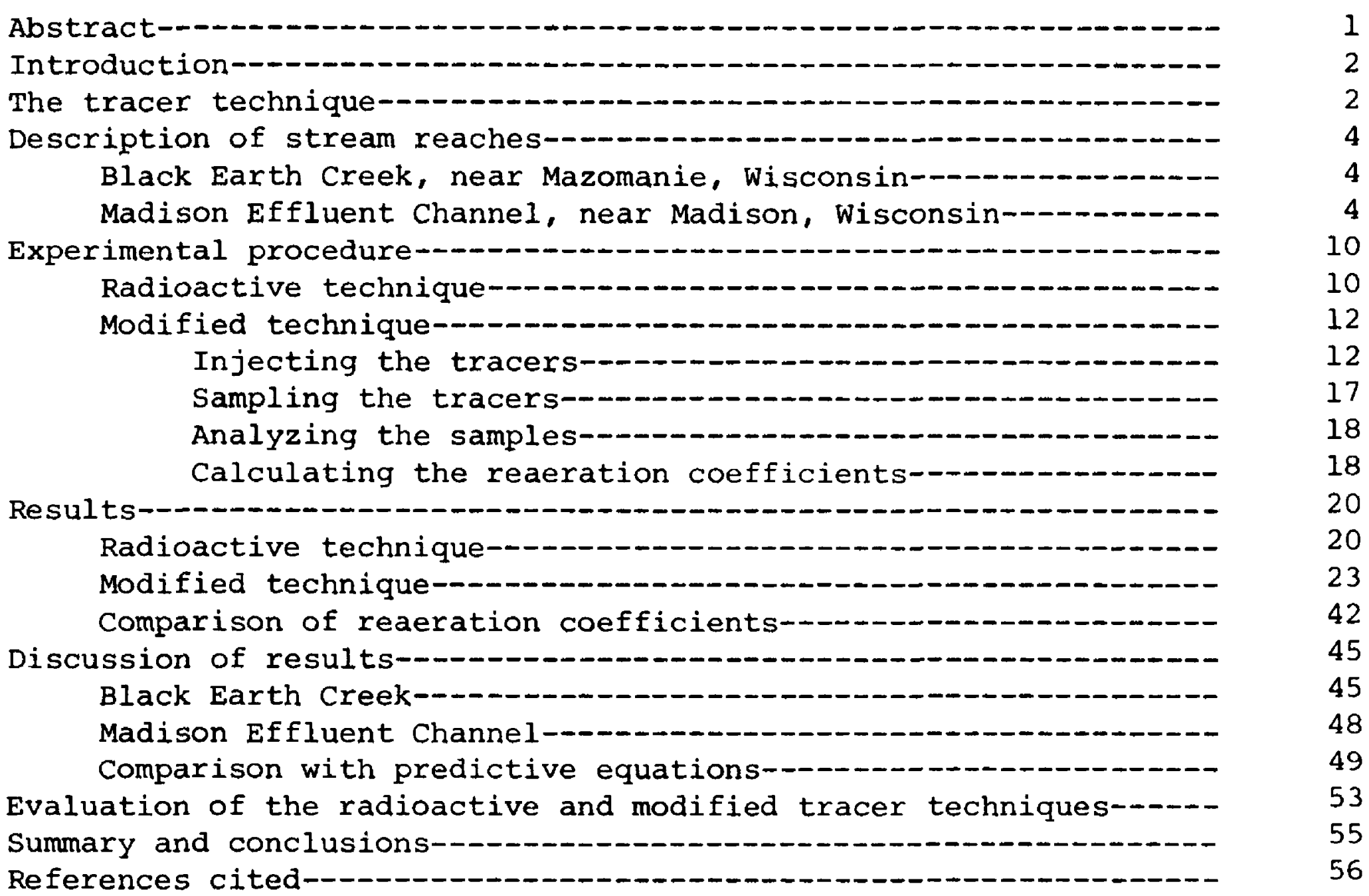

\section{ILLUSTRATIONS}

Figure 1. Map showing the location of the study sites in Wisconsin-- -

2. Map showing the location of the sampling cross sections on Black Earth Creek, near Mazomanie, Wisconsin--

3. Photograph showing a view of Black Earth Creek near Mazomanie, Wisconsin, looking upstream from cross-section 2----------

4. Photograph showing a view of Black Earth Creek near Mazomanie, Wisconsin, looking upstream from cross-section 3---------

5. Map showing the location of the sampling cross sections on the Madison Effluent Channel, near Madison, Wisconsin--

6. Photograph showing a view of the cascade aerator at the upstream end of the Madison Effluent Channel, near Madison, Wisconsinhotograph showing a view of the Madison Effluent Channel near Madison, Wisconsin, looking upstream from cross-section 2- 
Figure 8. Photograph showing a view of the Madison Effluent Channel near Madison, Wisconsin, looking upstream from cross-section 3--

9. Photograph showing a view of the porous tube diffusers and mounting frames for injecting the tracer gases--------

10. Photograph showing a view of the rotameters used for monitoring the flow rates of the tracer gases during the injection process

11. Graph showing concentrations of ethylene and propane as a function of time at cross-section 2, Black Earth Creek-

12. Graph showing concentrations of ethylene and propane as a function of time at cross-section 3 . Black Earth Creek-

13. Graph showing concentration of ethylene as a function of time at cross-section 4, Black Earth Creek----

14. Graph showing concentration of propane as a function of time at cross-section 4, Black Earth creek-n-c-

15. Graph showing concentration of rhodamine-WT dye as a function of time at cross-section 2, Black Earth Creek-_-_-_-_-_-

16. Graph showing concentration of rhodamine-WT dye as a function of time at cross-section 3, Black Earth Creek-

17. Graph showing concentration of rhodamine-WT dye as a function of time at cross-section 4 , Black Earth Creek--

18. Graph showing concentrations of ethylene and propane as a function of time at cross-section 2, Madison Effluent Channel-

19. Graph showing concentrations of ethylene and propane as a function of time at cross-section 3 , Madison Effluent Channel-

20. Graph showing concentrations of ethylene and propane as a function of time at cross-section 4, Madison Effluent Channel-

21. Graph showing concentration of rhodamine-WT dye as a function of time at cross-section 2, Madison Effluent Channel-

22. Graph showing concentration of chodamine-WT dye as a function of time at cross-section 3, Madison Effluent Channel-

23. Graph showing concentration of rhodamine-WT dye as a function of time at cross-section 4 , Madison Effluent Channel-_. 
TABLES

Page

Table 1. Injection periods, flow rates, weights injected, and cost of tracer gases, modified technique experiments------

2. Dose quantities, krypton/tritium ratios, and downstream krypton and tritium concentrations, radioactive technique experiments--

3. Measured reaeration coefficients, average water temperatures, and reaeration coefficients adjusted to $20^{\circ} \mathrm{C}$, radioactive technique experiments--.--

4. Peak concentrations and peak times for tracers, modified technique experiments--

5. Areas and centroids for tracer concentration-versustime curves, modified technique experiments-----

6. Time of travel for the Madison Effluent Channel experiments, as determined from the dye peak times--

7. Time of travel for the Black Earth Creek experiments, as determined from the dye peak times----

8. Measured reaeration coefficients and average water temperature, modified technique experiments------

9. Measured reaeration coefficients corrected to $20^{\circ} \mathrm{C}$, radioactive and modified technique experiments---

10. Percentage differences between radioactive and modified technique reaeration coefficients------

11. Percentage differences between radioactive and modified technique reaeration coefficients for the conditions of no dye loss and no increase in discharge, Madison Effluent Channel----

12. Experimental and predicted reaeration coefficients-

LIST OF SYMBOLS

Symbol

$a$

$A_{d}{ }^{A}{ }_{u}$

$A_{2}, A_{3}, A_{4}$
Definition

Constant in the equation relating the dyeloss correction factor and the peak time of travel

Area under the concentration-versus-time curve at the downstream and upstream ends of the reach, respectively

Area under the dye concentration-versustime curve at cross-sections 2,3 , and 4 , respectively
Units

Dimensionless

Microgram-minute/ liter

Microgram-minute/ liter 


\begin{tabular}{|c|c|c|}
\hline$b$ & $\begin{array}{l}\text { Exponent on the peak time of travel in the } \\
\text { equation relating the dye-loss correction } \\
\text { factor and the peak time of travel }\end{array}$ & Dimensionless \\
\hline$C_{D_{d}}, C_{D_{u}}$ & $\begin{array}{l}\text { Peak concentration of the dispersion-dilution } \\
\text { tracer at the downstream and upstream ends of } \\
\text { the reach, respectively }\end{array}$ & $\begin{array}{l}\text { Microgram/ } \\
\text { liter }\end{array}$ \\
\hline$C_{H_{d}}, C_{H}$ & $\begin{array}{l}\text { Peak concentration of tritium at the down- } \\
\text { stream and upstream ends of the reach, } \\
\text { respectively }\end{array}$ & $\begin{array}{l}\text { Microcurie/ } \\
\text { milliliter }\end{array}$ \\
\hline$C_{\mathrm{Kr}}, C_{\mathrm{Kr}}$ & $\begin{array}{l}\text { Peak concentration of krypton at the } \\
\text { downstream and upstream ends of the reach, } \\
\text { respectively }\end{array}$ & $\begin{array}{l}\text { Microcurie/ } \\
\text { milliliter }\end{array}$ \\
\hline$C_{T_{d}}, C_{T}$ & $\begin{array}{l}\text { Peak concentrations of the tracer gas at the } \\
\text { downstream and upstream ends of the reach, } \\
\text { respectively }\end{array}$ & $\begin{array}{l}\text { Microgram/ } \\
\text { liter }\end{array}$ \\
\hline$C(t)$ & Concentration of tracer at time $t$ & $\begin{array}{l}\text { Microgram/ } \\
\text { liter }\end{array}$ \\
\hline$J_{3}, J_{4}$ & $\begin{array}{l}\text { Dye loss correction factors for reaches } \\
2-3 \text { and } 3-4 \text {, respectively }\end{array}$ & Dimensionless \\
\hline$K_{E}$ & Desorption coefficient for ethylene, base e & 1/day \\
\hline$K_{\mathrm{Kr}}$ & Desorption coefficient for krypton, base e & 1/day \\
\hline$K_{P}$ & Desorption coefficient for propane, base e. & \$day \\
\hline$K_{T}$ & $\begin{array}{l}\text { Desorption coefficient for the tracer gas, } \\
\text { base e }\end{array}$ & $1 /$ day \\
\hline$K_{2}$ & Reaeration coefficient, base e & 1/day \\
\hline$K_{2}$ MOD & $\begin{array}{l}\text { Reaeration coefficient, base e, measured } \\
\text { with the modified tracer technique }\end{array}$ & 1/day \\
\hline$K_{2}$ & $\begin{array}{l}\text { Reaeration coefficient, base e, measured } \\
\text { with the radioactive tracer technique }\end{array}$ & 1/day \\
\hline$K_{20}$ & Reaeration coefficient, base $e$, at $20^{\circ}$ Celsius & 1/day \\
\hline$K_{2}$ & $\begin{array}{l}\text { Reaeration coefficient, base } e \text {, at temperature } \\
\tau \text { where } \tau \text { is the water temperature in degrees } \\
\text { Celsius }\end{array}$ & 1/day \\
\hline$Q_{d^{\prime}} Q_{u}$ & $\begin{array}{l}\text { Water discharge at the downstream and upstream } \\
\text { ends of the reach, respectively }\end{array}$ & $\begin{array}{l}\text { Cubic meter/ } \\
\text { second }\end{array}$ \\
\hline
\end{tabular}




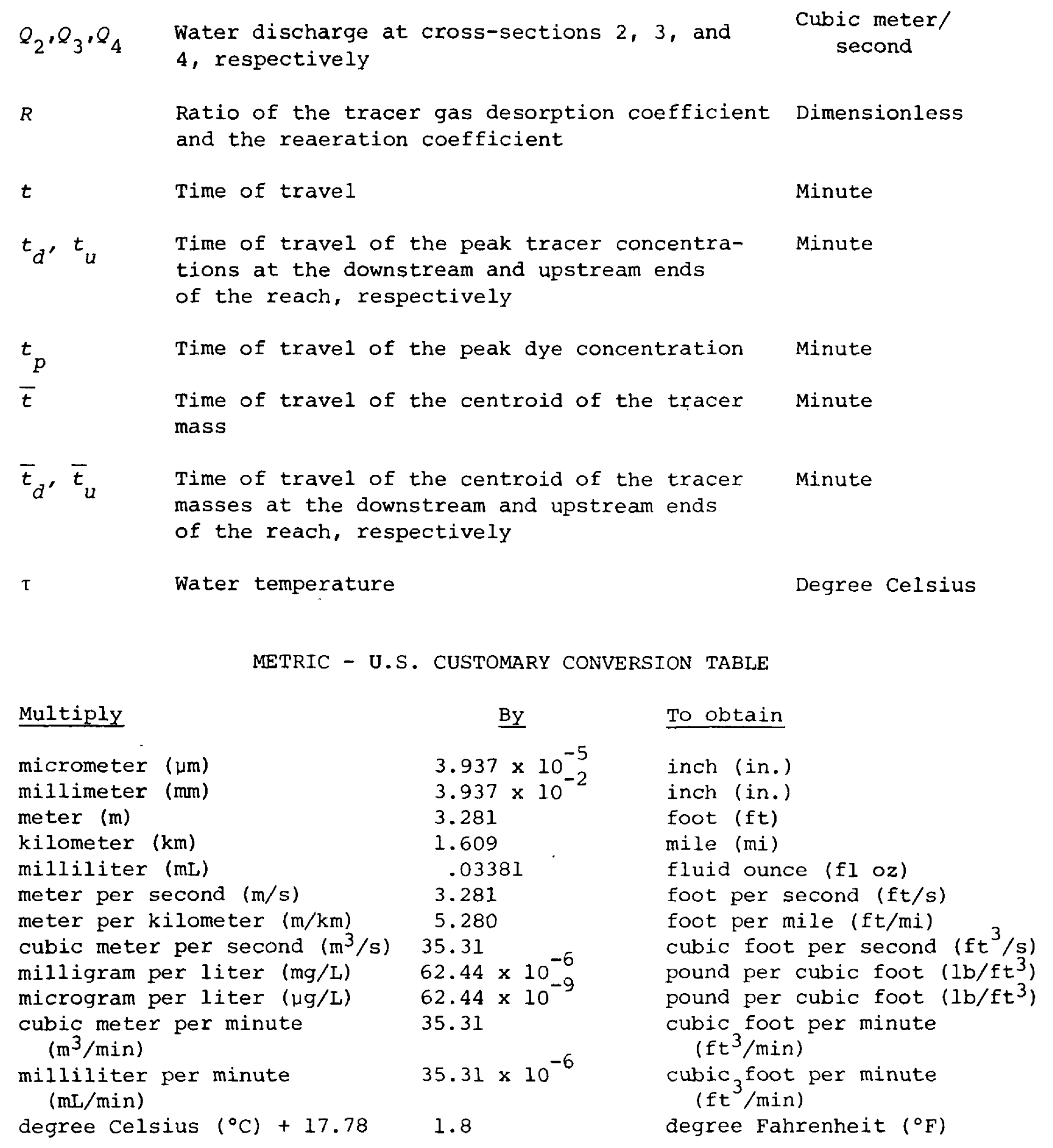




\begin{abstract}
COMPARISON OF THE RADIOACTIVE AND
MODIFIED TECHNIQUES FOR MEASUREMENT

OF STREAM REAERATION COEFFICIENTS
\end{abstract}

By R. E. Rathbun and R. S. Grant

\begin{abstract}
The radioactive and modified tracer techniques were used to measure the reaeration coefficients of two reaches each of Black Earth Creek and the Madison Effluent Channel near Madison, Wis. Comparison of the results showed that coefficients measured with the modified technique ranged from -8.96 to +3.61 and from +15.7 to +32.2 percent different from the coefficient measured with the radioactive tracer technique on the two reaches of Black Earth Creek. The larger coefficients measured with the modified technique on the second reach were attributed to increased wind conditions during the latter part of the modified-technique experiment. Interpretation of the results of the Madison Effluent Channel study was complicated by an unsteady flow condition during the modified-technique experiment. It was necessary to estimate the part of the reduction in the area under the dye concentration-versus-time curve that was the result of dye loss and the part that was the result of the increase in water discharge. Using these estimated values, the coefficients measured with the modified technique ranged from +25.3 to +57.9 and from -4.74 to +2.94 percent different from the coefficient measured with the radioactive technique on the two reaches of the Madison Effluent Channel.

Reaeration coefficients were predicted for the 4 stream reaches with 19 predictive equations from the literature. The range of the predicted coefficients for each of the reaches varied from about a 6-fold range for the first reach of the Madison Effluent Channel to an almost 11-fold range for the second reach of Black Earth Creek.

There are advantages and disadvantages to both the radioactive and modified tracer techniques. The main advantage of the radioactive technique is that the tracer gas is chemically inert; the main disadvantage is that a radioactive isotope of the gas must be used to obtain the necessary analytical sensitivity. The main advantage of the modified technique is that radioactive tracers are not necessary; the main disadvantage is that the hydrocarbon tracer gases may be subject to biological degradation and sorption losses. Results of this comparison study suggest that the modified technique is a promising alternative to the use of radioactive tracers.
\end{abstract}




\section{INTRODUCTION}

The management of the water quality of our streams and rivers requires that the reaeration coefficient, $K_{2}$, be known. It is this coefficient that characterizes the reaeration process, which is the physical absorption of oxygen from the atmosphere by the flowing stream.

The reaeration coefficient of a stream can be predicted using any of a number of equations from the literature. However, it is well known that these equations give a wide range of predicted coefficients for a specific set of hydraulic conditions on a specific stream. Also an evaluation (Rathbun, 1977) of these equations showed that an equation that predicted coefficients well for one stream did not necessarily predict coefficients well for another stream.

The reaeration coefficient of a stream can be measured using the dissolved-oxygen balance, the disturbed equilibrium, or the tracer technique. An analysis of these techniques (Bennett and Rathbun, 1972) showed that the tracer technique was far superior to the other two techniques. The tracer technique, however, requires the use of radioactive tracers, and thus there are controls and restrictions on the use of the technique. A modified tracer technique not requiring radioactive tracers was developed (Rathbun, Shultz, and Stephens, 1975), and preliminary results were encouraging. To evaluate further the modified technique, it was considered desirable to compare the radioactive and modified tracer techniques. This report describes two comparison runs completed on Black Earth Creek and the Madison Effluent Channel near Madison, Wis.

\section{THE TRACER TECHNIQUE}

The basis of the tracer technique is the observation that the ratio of the rate coefficient for the tracer gas desorbing from water to the rate coefficient for oxygen being absorbed by the same water is a constant that is independent of mixing conditions and the temperature of the water. Therefore,

$$
K_{2}=K_{T} / R
$$

where $K_{2}$ is the absorption coefficient for oxygen which is the reaeration coefficient, $K_{T}$ is the desorption coefficient for the tracer gas, and $R$ is the ratio of the coefficients, $K_{T} / K_{2}$. The ratio is determined from a series of laboratory stirred-tank experiments in which the reaeration and desorption coefficients are measured simultaneously. Details of these laboratory studies for the radioactive and modified tracer techniques were described by Tsivoglou and others (1965) and Rathbun, Stephens, Shultz, and Tai (1978), respectively.

Application of the tracer technique consists of injecting into the stream a quantity of the tracer gas together with a conservative tracer that permits adjustment of the gas concentrations for the effects of dispersion 
and any dilution that might occur as the result of flow accrual. Samples are obtained at various points downstream so that concentrations of the gas and dispersion-dilution tracers can be determined. From these concentrations, the desorption coefficient for the tracer gas is calculated from

$$
K_{T}=\frac{1}{t_{d}-t_{u}} \log _{e} \frac{\left(\frac{C_{T}}{C_{D}}\right)_{u}}{\left(\frac{C_{T}}{C_{D}}\right)_{d}}
$$

where $K_{T}$ is the base e desorption coefficient for the tracer gas, $t$ is the time of travel of the peak concentrations, $C_{T}$ and $C_{D}$ are the peak concentrations of the gas and dispersion-dilution tracers, respectively, and the $d$ and $u$ subscripts indicate the downstream and upstream ends of the reach, respectively. The desorption coefficient calculated from equation 2 is converted to the reaeration coefficient with equation 1 .

The radioactive tracer technique consists basically of injecting as an instantaneous point source a mixture of radioactive krypton, tritium, and rhodamine-WT dye into the stream. The krypton is the tracer gas, tritium is the dispersion-dilution tracer, and the rhodamine-WT dye is used to indicate when to sample for the two radioactive tracers. Because the tracers are all injected at the same point in time and spare, no mixing zone is necessary, and the first sampling point is usually a short distance below the injection point. Details of the application of the radioactive tracer technique were presented by Tsivoglou (1967), Tsivoglou and others (1968), Tsivoglou and Wallace (1970, 1972), Tsivoglou and others (1972), and Tsivoglou (1974).

The modified tracer technique consists basically of injecting as a short continuous injection a low molecular weight hydrocarbon gas, either ethylene or propane, and a rhodamine-WT dye and water solution into the stream. A continuous injection is used because the solubilities of ethylene and propane in water are so small that an instantaneous point-source injection would require a quantity of tracer solution too large to handle easily for most streams. The injection is continued only long enough to get sufficient tracer gas into the stream to permit accurate determination of the concentrations. Thus, although plateau concentrations may be obtained at the first measurement cross section, only peak concentrations will be obtained at downstream cross sections. Rhodamine-WT dye is used as the dispersion-dilution tracer; however, it is generally recognized that this dye is not completely conservative. Therefore, complete dye concentration-versus-time curves are obtained at the upstream and downstream ends of the reach together with discharge measurements at these cross sections to permit correction for dye loss. The gas and dye tracers are injected for the same time period, but because they are not injected over exactly the same small width increment of the cross section, the first sampling cross section is located usually about 0.75 hours time-of-travel downstream to permit mixing of the 
tracers over the width of the stream. The basic procedures of the modified tracer technique were presented by Rathbun, Shultz, and stephens (1975).

\title{
DESCRIPTION OF STREAM REACHES
}

\author{
Black Earth Creek, near Mazomanie, Wisconsin
}

The study reach on Black Earth Creek was the 8.4-km section starting just downstream from the municipal wastewater treatment plant of Mazomanie, and ending about $0.8 \mathrm{~km}$ above the mouth at Blue Mounds Creek. Figure 1 shows the general location of the study site, and figure 2 shows the details of the study reach including the locations of the sampling cross sections. Black Earth Creek is a pool-and-riffle stream and meanders through open agricultural land. The streambed is composed primarily of sand, gravel, and cobbles, and the slope of the streambed averages 0.80 $\mathrm{m} / \mathrm{km}$. The water discharge on the day of the comparison experiment was about $1.1 \mathrm{~m} / \mathrm{s}$, and the average water velocity determined from the dye tracers was about $0.34 \mathrm{~m} / \mathrm{s}$. The depth of flow ranged from about $0.06 \mathrm{~m}$ in the riffles to about $0.9 \mathrm{~m}$ in the deepest pools. Figure 3 is a photograph of Black Earth Creek looking upstream from cross-section 2, and figure 4 is a photograph looking upstream from cross-section 3. Five-day BOD (biochemical oxygen demand) values ranged from 3.0 to 2.5 $\mathrm{mg} / \mathrm{L}$ at cross-sections 1 and 4 , respectively, and water temperatures ranged from about $20^{\circ} \mathrm{C}$ to $24^{\circ} \mathrm{C}$ through the reach during the comparison experiment.

\section{Madison Effluent Channel, near Madison, Wisconsin}

The city of Madison is located in southern Wisconsin (fig...1), and the effluent from the wastewater treatment plant is carried through a buried aqueduct which surfaces south of the city. The effluent exits from the buried aqueduct through a cascade aerator and then flows into the Madison Effluent Channel. Figure 5 is a map showing the location of the effluent channel, and figure 6 is a photograph of the aerator. The effluent contained large concentrations of detergent as is evidenced by the foam on the surface.

The 7.8-km reach starting about $75 \mathrm{~m}$ downstream from the cascade aerator was used for the study reach. Figure 5 shows the location of the study reach including the locations of the sampling cross sections. The effluent channel is an excavated ditch with gentle curves and a cross section that is approximately uniform over the length of the reach. The banks are steep and covered primarily with long grass. The channel contains little debris, although fairly heavy growths of aquatic weeds are present. The streambed is composed mostly of gravel in the higher velocity segments and mud in the other segments. The slope of the streambed averages $0.72 \mathrm{~m} / \mathrm{km}$. A second cascade aerator with an elevation change of about $1.2 \mathrm{~m}$ is located between cross-sections 3 and 4. The water discharge on the day of the comparison studies ranged between 1.4 and $2.0 \mathrm{~m}^{3} / \mathrm{s}$, and the average water velocities for the study 


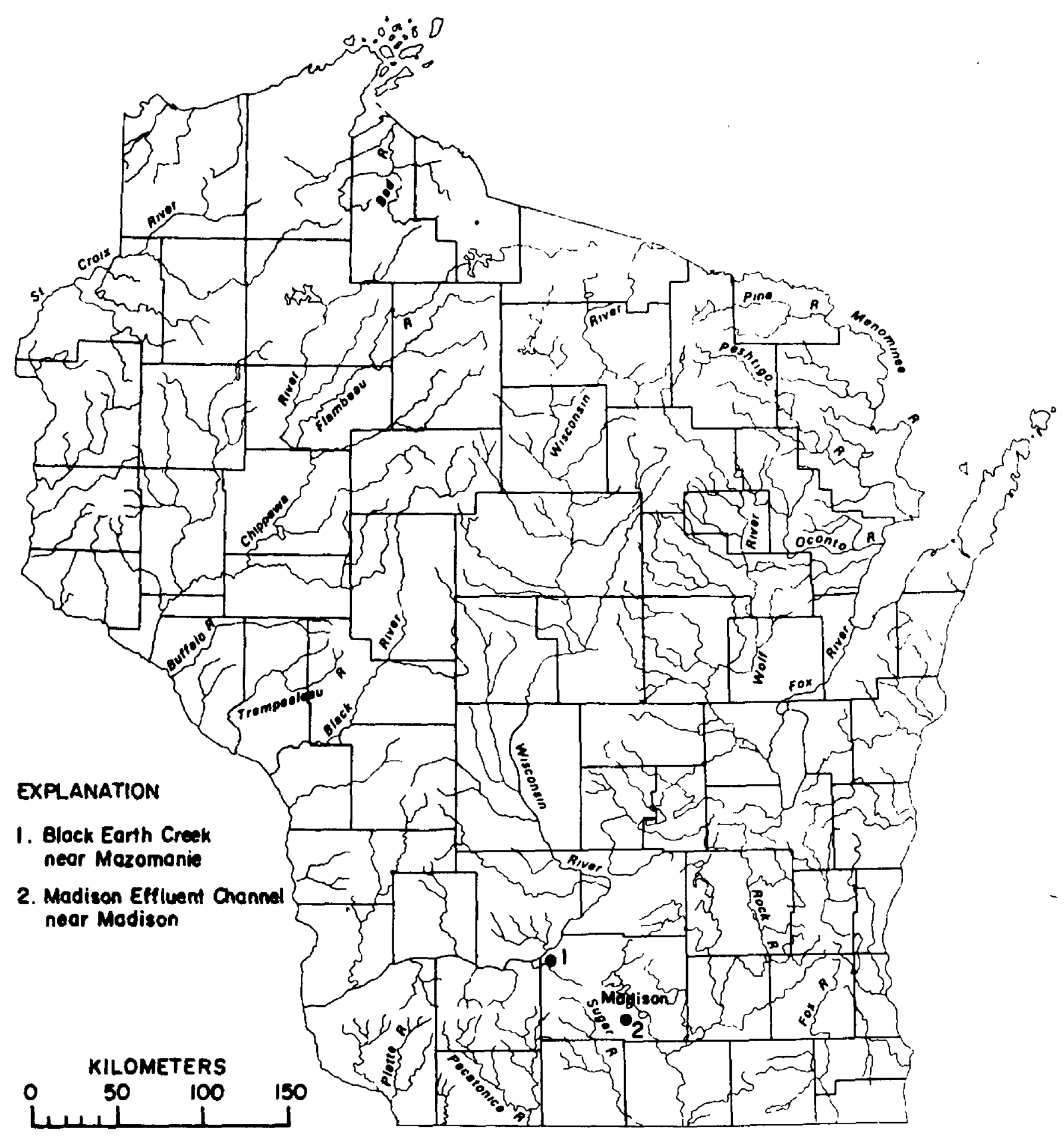

Figure 1.--Location of study sites in Wisconsin. 


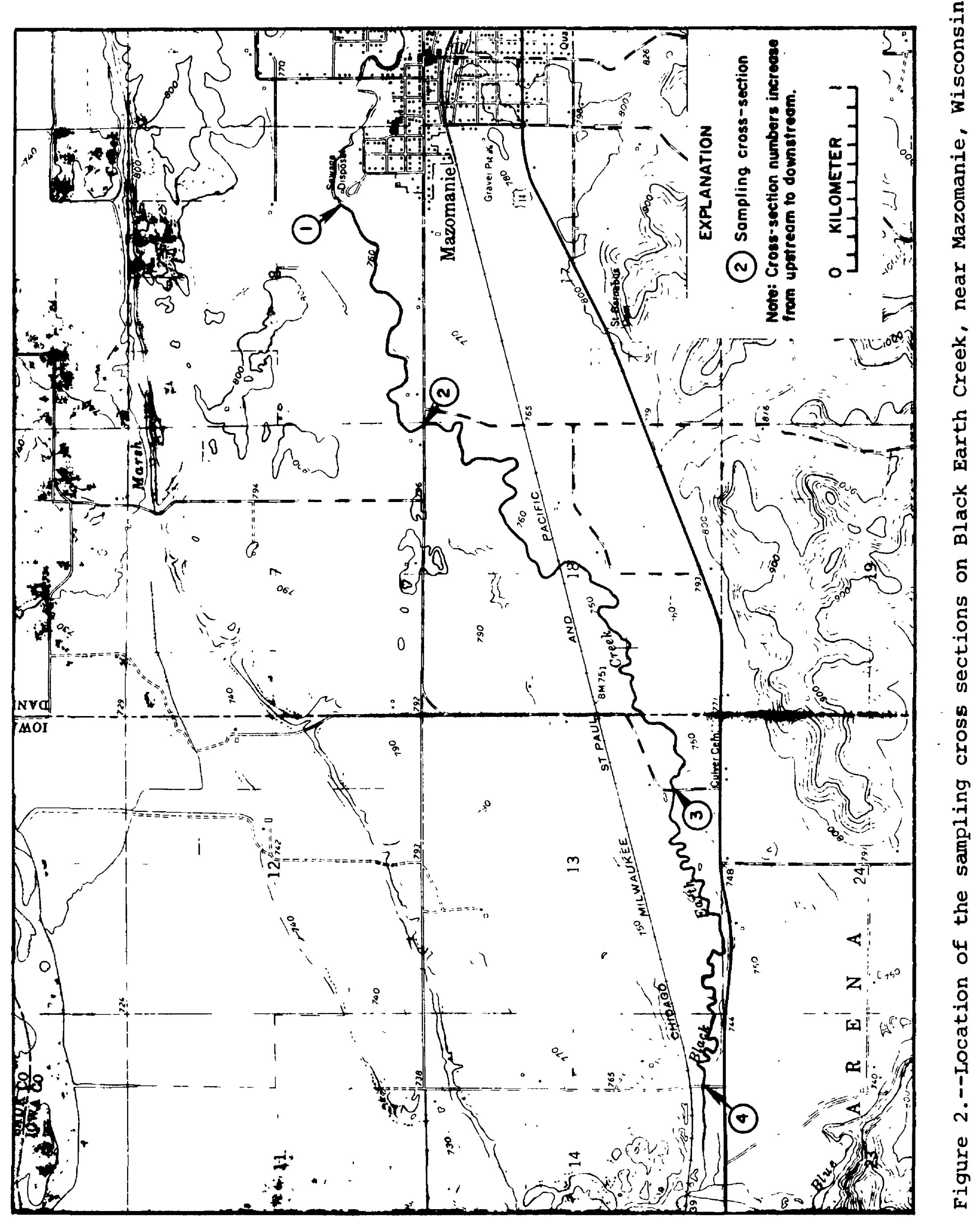




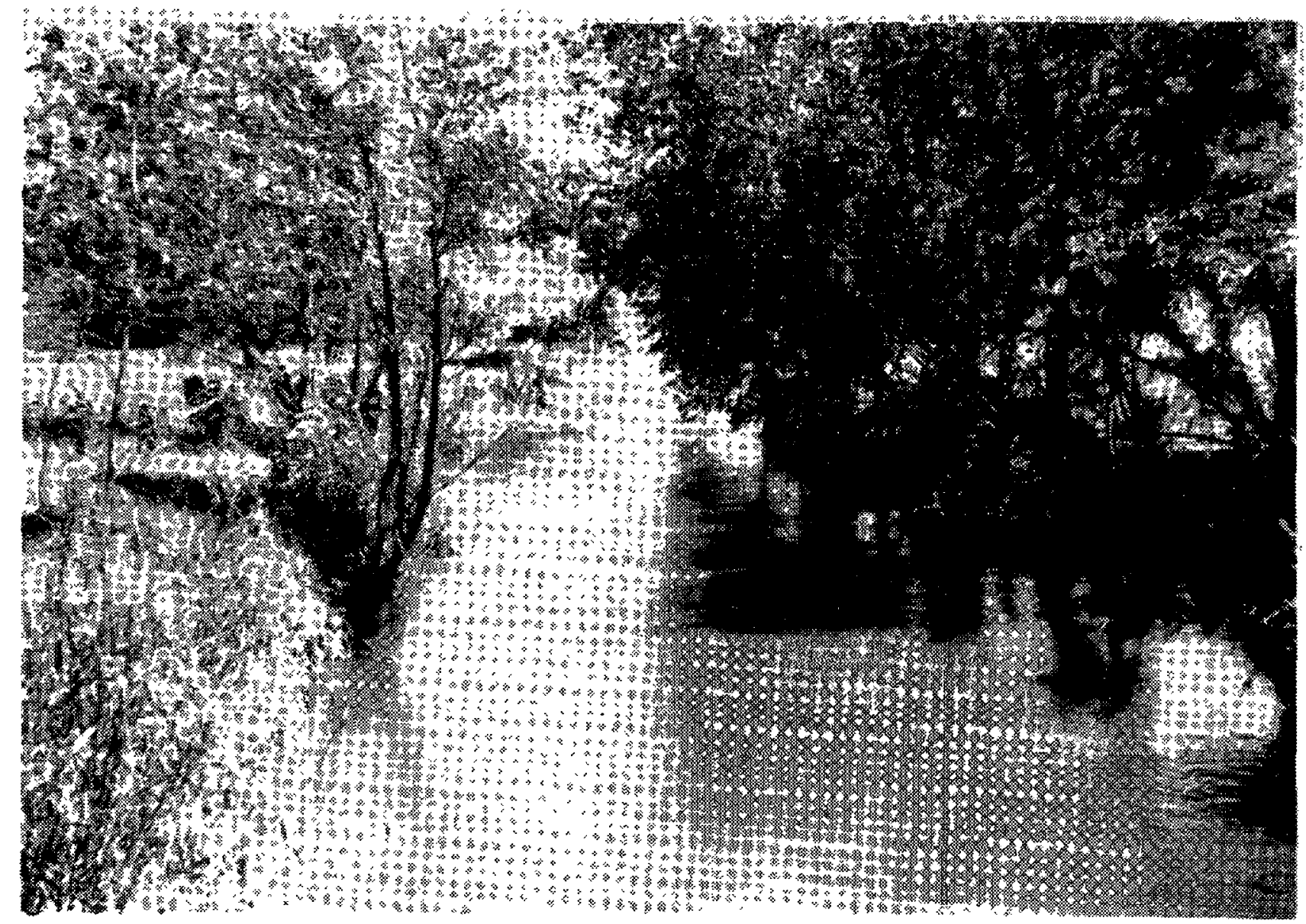

Figure 3.--View of Black Earth Creek near Mazomanie, Wisconsin, lookıng upstream from cross-section 2.

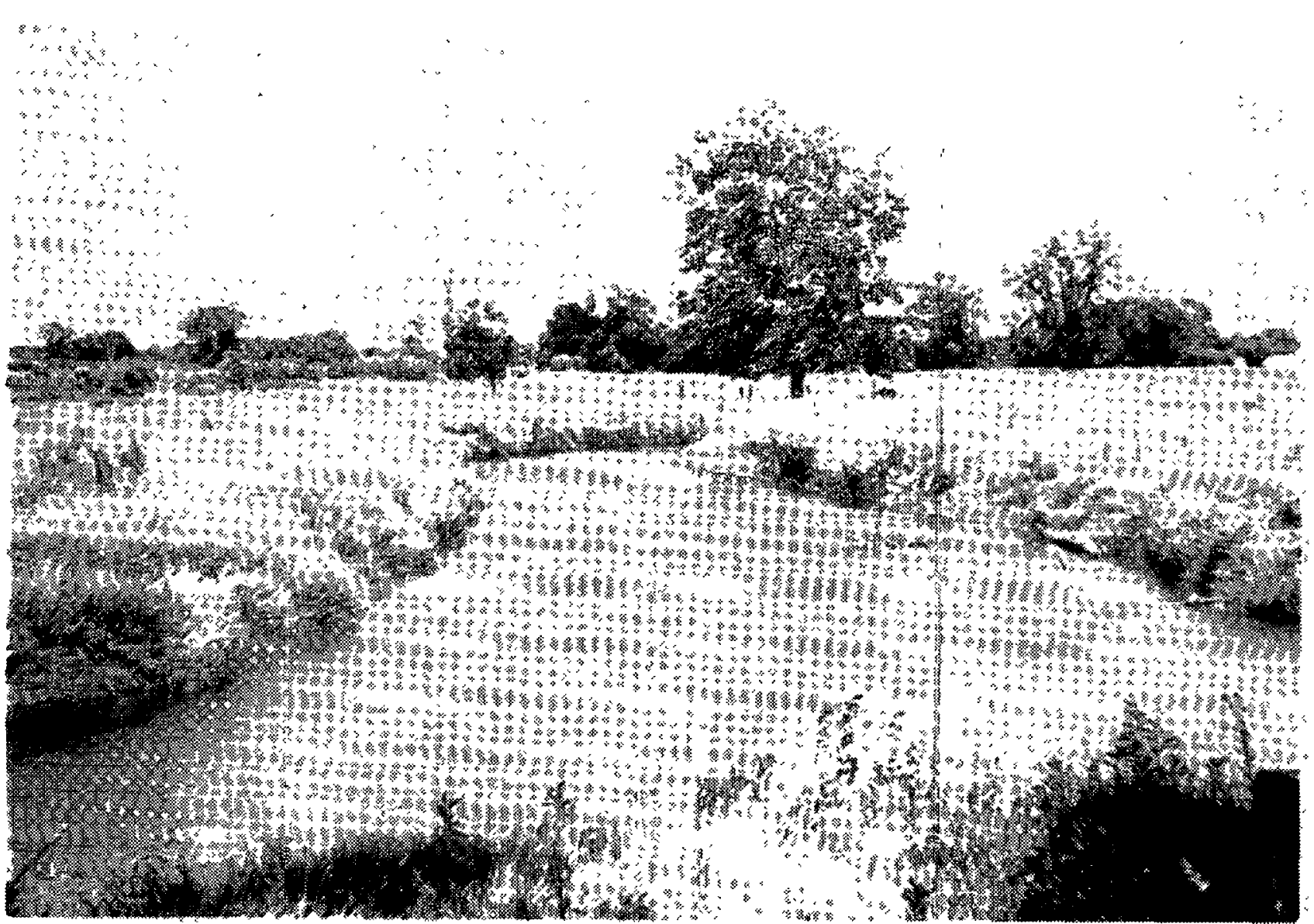

Figure 4.--View of Black Earth Creek near Mazomanie, Wisconsin, looking upstream from cross-section 3 . 


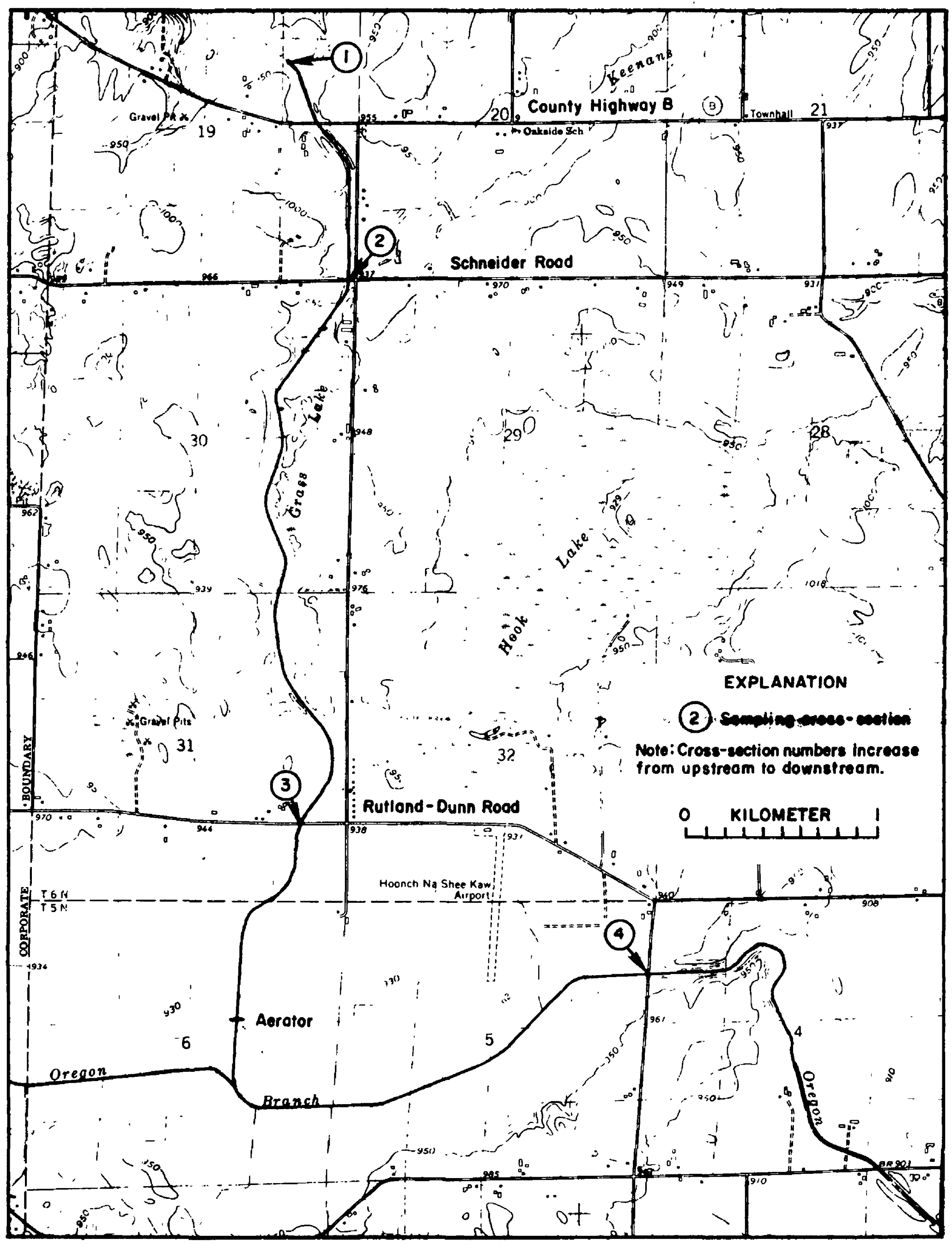

Figure 5.--Location of the sampling cross sections on the Madison Effluent Channel, near Madison, Wisconsin. 


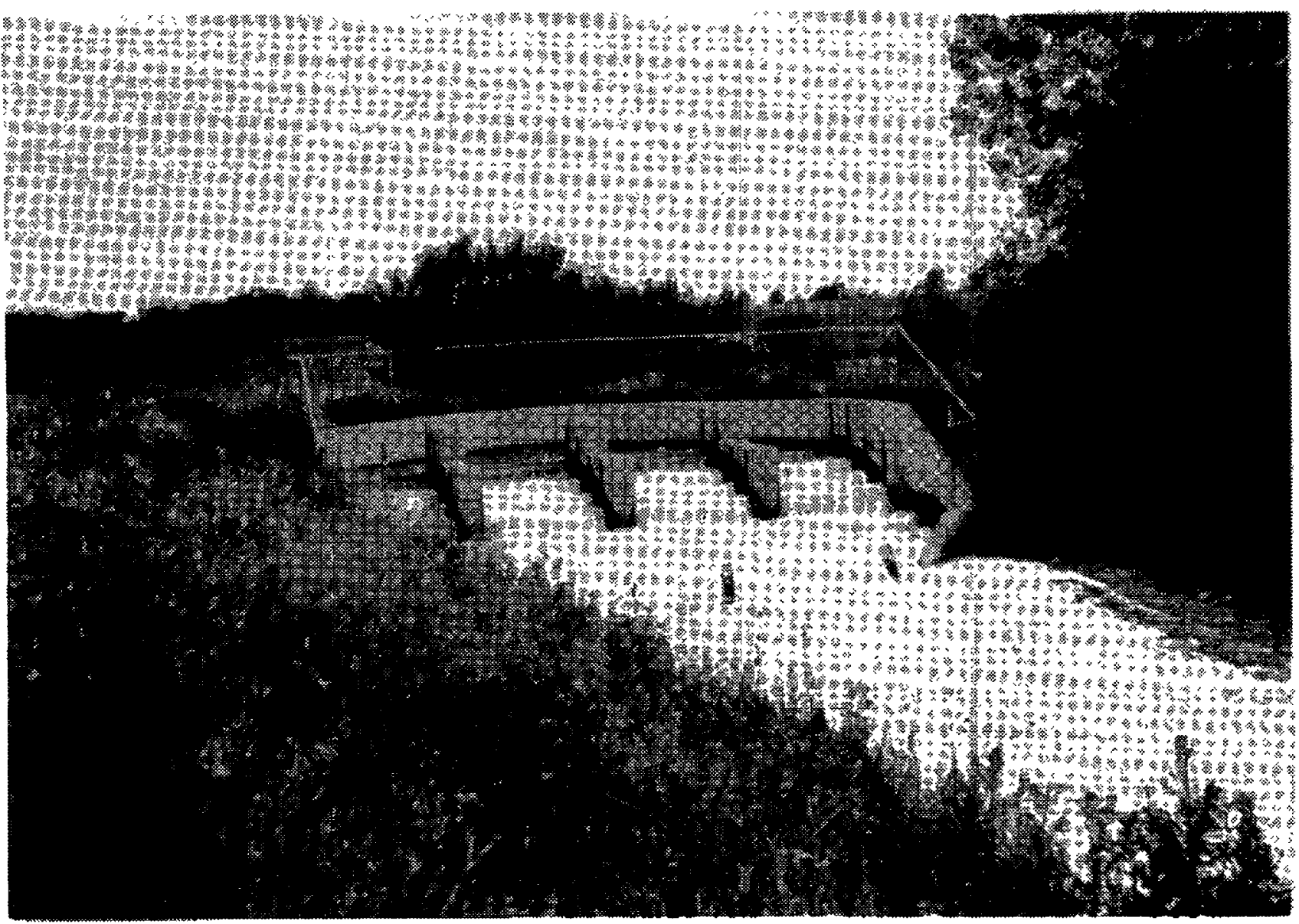

Figure 6.--View of the cascade aerator at the upstream end of the Madison Effluent Channel, near Madison, Wisconsin. 
reach determined from the dye tracers ranged from 0.34 to $0.38 \mathrm{~m} / \mathrm{s}$. The depth of flow ranged from 0.6 to $1.2 \mathrm{~m}$. Figures 7 and 8 are photographs looking upstream from cross-sections 2 and 3, respectively. Figure 7 shows that the detergent foam that was so evident at cross-section 1 (fig. 6) has disappeared at cross-section 2 which was about $1.1 \mathrm{~km}$ and about 0.8 hour time-of-travel downstream. Five-day BOD values ranged from 11.0 to $14.0 \mathrm{mg} / \mathrm{L}$ at cross-sections 1 and 4 , respectively, and the 28-day BOD was $112 \mathrm{mg} / \mathrm{L}$ at both cross sections. Water temperatures were about $20^{\circ} \mathrm{C}$ during the comparison experiment.

\section{EXPERIMENTAL PROCEDURE}

\section{Radioactive Technique}

The radioactive tracer technique used in this study for measurement of reaeration coefficients was based on that developed by Tsivoglou (1967) for the Federal water Pollution Control Administration. The method employs two radioisotopes, krypton-85 $\left({ }^{85} \mathrm{Kr}\right)$, a noble gas (tracer for oxygen), and hydrogen-3 $\left({ }^{3} \mathrm{H}\right)$, as tritiated water (the dispersiondilution tracer). A third tracer, rhodamine-WT fluorescent dye, is used with the $85 \mathrm{Kr}$ and $3 \mathrm{H}$ for time-of-travel determination and also as a radiotracer-sampling indicator. The tritium is assumed to be conservative for all practical purposes, and the krypton is assumed to be lost from the stream only by desorption through the surface of the stream.

The tracers are released by breaking a glass container under water to get an instantaneous point source injection. The peak tracer concentrations decrease downstream because of dispersion and dilution, and some ${ }^{85} \mathrm{Kr}$ gas also escapes from the water surface into the atmosphere because of the normal exchange produced by stream turbulence. Greater turbulence increases the rate at which ${ }^{85} \mathrm{Kr}$ escapes from the water and consequently the rate at which atmospheric oxygen can enter the water.

The peak ${ }^{85} \mathrm{Kr}$ concentration decreases faster than the peak ${ }^{3} \mathrm{H}$ concentration with the difference in rate being the rate of desorption of the ${ }^{85} \mathrm{Kr}$. Laboratory studies by Tsivoglou (1967) showed that the rate coefficient for ${ }^{85} \mathrm{Kr}$ escaping from water into the atmosphere is 83 percent of that for oxygen entering the water from the atmosphere, and that this percentage is independent of the degree of turbulence and temperature within the range from $13^{\circ} \mathrm{C}$ to $32^{\circ} \mathrm{C}$. Determination of the desorption coefficient of $85 \mathrm{Kr}$ in a reach of stream is then readily converted into the reaeration coefficient commonly designated $K_{2}$.

At sampling cross sections downstream from the tracer-injection point, the stream water is sampled at about the center of the flow as the tracers flow past. Presence of the tracers is known because the fluorescent dye is detected concurrently in the field by a fluorometer. Water samples taken during the dye peaks are used in laboratory determinations of ${ }^{85} \mathrm{Kr}$ and ${ }^{3} \mathrm{H}$ concentrations using a liquid scintillation counter. Samples collected at other times of travel could be used, however, analysis of the samples at the peaks provides the most accurate determination of the concentrations. 

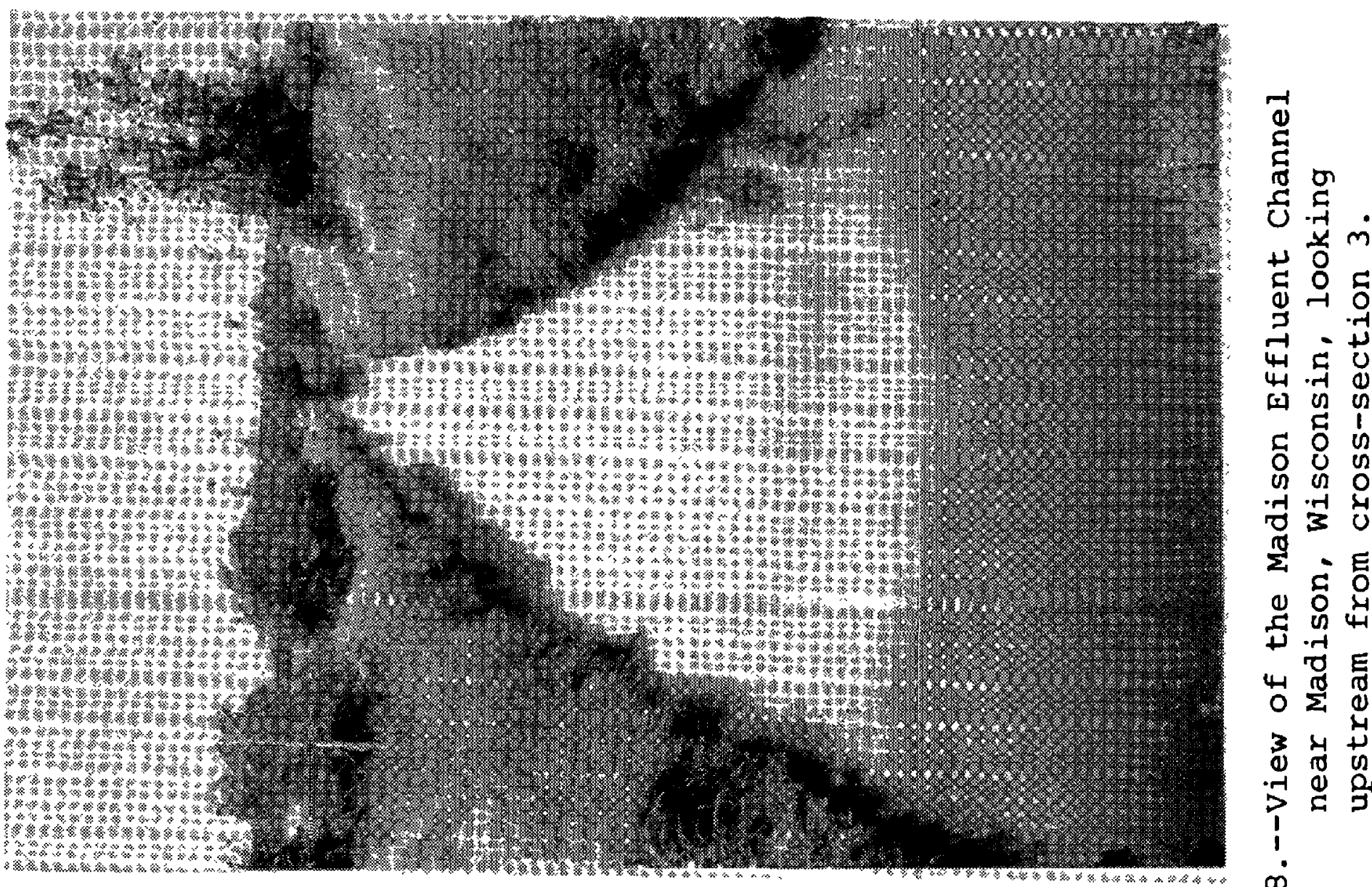

岁

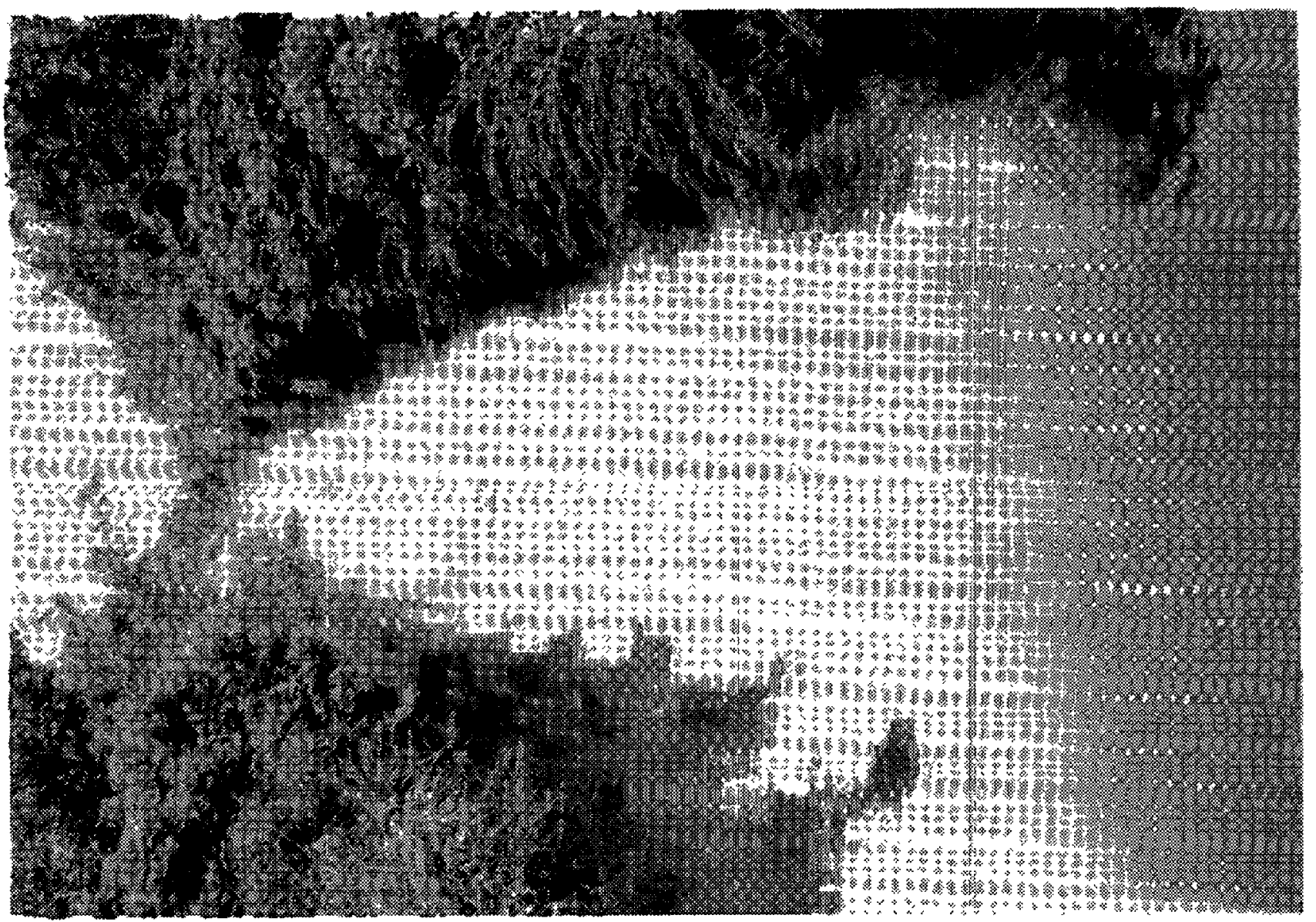

ํㅜㅇ

거옹

蛋

望

ठ 。

$+$

ఫ

넌

ज्ञ

돌

थ

范

$\Sigma$ U

越资

स हो U

$\begin{array}{lll}0 & 0 & 1 \\ 0 & \text { in }\end{array}$

3 .

ब

$>\sum 0$

岂 
The desorption coefficient for ${ }^{85} \mathrm{Kr}$ is computed from equation 1 which for the radioactive tracer technique has the form

$$
K_{\mathrm{Kr}}=\frac{1}{t_{d}-t_{\mathrm{u}}} \log _{\mathrm{e}} \frac{\left(C_{\mathrm{Kr}} / C_{H}\right)_{\mathrm{u}}}{\left(C_{\mathrm{Kr}} / C_{H}\right)_{d}}
$$

where $K_{\mathrm{Kr}}$ is the base e desorption coefficient of ${ }^{85} \mathrm{Kr}$; $t$ is the time of travel of the peak concentrations; $\left(C_{\mathrm{Kr}} / C_{H}\right)$ is the ratio of the concentrations of ${ }^{85} \mathrm{Kr}$ and ${ }^{3} \mathrm{H}$; and the $u$ and $d$ subscripts indicate the upstream and downstream ends of the reach, respectively. The reaeration coefficient, $k_{2}$, is computed from

$$
K_{2}=\frac{K_{\mathrm{Kr}}}{0.83}
$$

A more complete discussion of the theory, field, laboratory, and computation procedures has been published by Tsivoglou and others $(1965,1968)$, Tsivoglou and Wallace (1972), and Tsivoglou (1967, 1974).

\section{Modified Technique}

The modified technique uses a low molecular weight hydrocarbon gas such as ethylene or propane as the gas tracer and rhodamine-WT dye as the dispersiondilution tracer. In some studies, including the present, the two tracer gases were used simultaneously. Use of the two gases, which have different desorption characteristics, permits two determinations of the reaeration coefficient in one experiment with only a little additional work relative to that required with a single gas. The modified technique uses rhodamine-WT dye as the dispersion-dilution tracer and because this dye is not totally conservative, discharge and complete dye concentration-versus-time curves must be determined at each cross section to permit corrections for dye losses.

The measurement of a reaeration coefficient by the modified technique requires injecting the tracers into the stream, sampling the tracers at downstream points and measuring the water discharge, analyzing the water samples to determine the concentrations of the tracers, and calculating the reaeration coefficients from the data.

Injecting the tracers.--The ethylene and propane were injected into the stream by bubbling the gases through porous tube diffusers such as those used for aeration in sewage treatment plants. The diffusers, obtained from the Norton Co., 1/ Worcester, Mass., were $0.46 \mathrm{~m}$ long, 76 $\mathrm{mm}$ in outside diameter, and $19 \mathrm{~mm}$ thick. Two diffusers were used for propane, one for ethylene. A larger surface area was needed for propane

\footnotetext{
1/ The use of the brand names in this report is for identification purposes only and does not imply endorsement by the U.S. Geological Survey.
} 
because the solubility in water, $62.4 \mathrm{mg} / \mathrm{L}$ at room temperature $\left(25^{\circ} \mathrm{C}\right)$ is less than half that of ethylene, $131 \mathrm{mg} / \mathrm{L}$ at room temperature (McAuliffe, 1966). The approximate average pore size of the diffusers was $6.3 \mu \mathrm{m}$ for the propane diffusers and between 15 and $20 \mu \mathrm{m}$ for the ethylene diffuser. The diffusers were mounted in frames constructed from steel plate and pipe. Figure 9 is a photograph of the diffuser tubes mounted in the frames.

The three diffuser-frame assemblies were placed on the bottom of the stream at the point in the cross section where the flow was largest. The gases were fed directly from the cylinders in which they were supplied through two-stage regulating valves and rotameters for monitoring the flow rates to the diffusers. Technical grade ethylene and C.P. grade propane from the Air Products Co. were used. Figure 10 is a photograph of the rotameters used for monitoring the flow rates. A part of the propane cylinder and regulating valve can be seen at the left side of the photograph.

The short continuous injection of the tracers will usually give plateau concentrations at the first cross section that are reduced to peaks at downstream cross sections as a result of the effect of longitudinal dispersion.

The gas flow rates and the length of the injection period were adjusted to give peak gas concentrations at the downstream end of the reach of about $1 \mu \mathrm{g} / \mathrm{L}$. This concentration could be determined with good precision by the gas chromatographic analysis procedure used for determining the gas concentrations. The concentration remaining at the downstream end of the reach depends first upon the concentration of gases obtained in the water at the injection point and then the characteristics of the reach such as the reaeration coefficient, the dispersion coefficient, time of travel, and flow accrual.

Experience has shown that ethylene and propane flow rates of about 0.015 and 0.020 standard $\mathrm{m}^{3} / \mathrm{min}$, respectively, with injection periods of about 1 hour are generally sufficient for streams of the type of Black Earth Creek and the Madison Effluent Channel with water discharges in the range from 0.7 to $2.0 \mathrm{~m}^{3} / \mathrm{s}$ and velocities in the range from 0.2 to $0.4 \mathrm{~m} / \mathrm{s}$. The concentrations of the tracer gases obtained in the stream at the injection point depend on the efficiency of the injection process. The efficiency depends on the flow rates of the gases through the diffusers, the depth and velocity of the water over the diffusers, and the water temperature which determines the solubility and thus the driving force for absorption. No attempt was made to optimize the injection process because the gases are inexpensive and only small amounts are needed.

The injection periods, approximate flow rates, quantities of the gases injected, and the cost of the gases used in the experiments are presented in table 1 . 


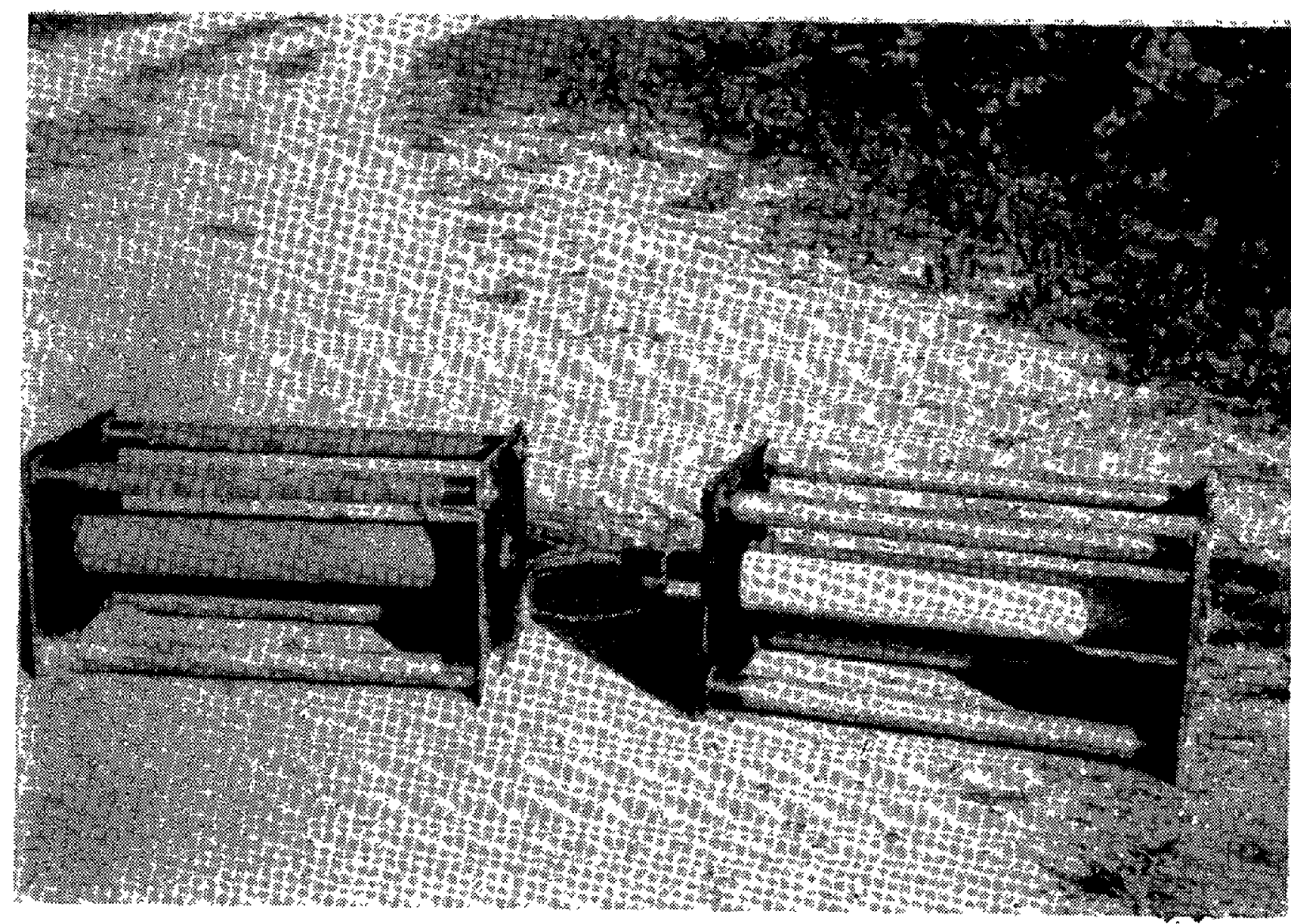

Figure 9.--Porous tube diffusers and mounting frames for injecting the tracer gases; the tubes are $0.46 \mathrm{~m}$ long; ethylene diffuser on the left, propane diffuser on the right. 


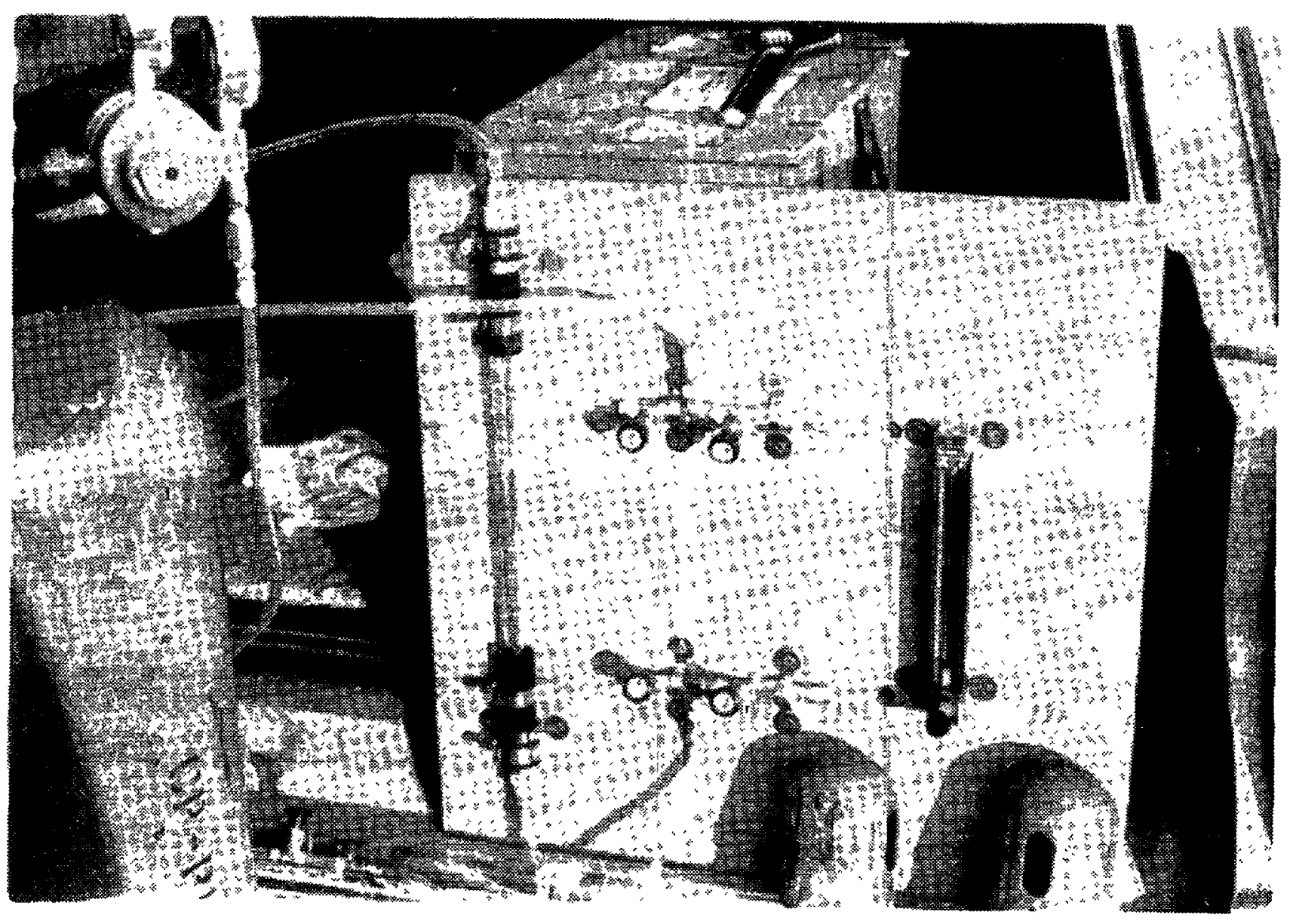

Figure 10.--View of the rotameters used for monitoring the flow rates of the tracer gases during the injection process; a part of the propane cylinder and regulating valve can be seen at the left. 


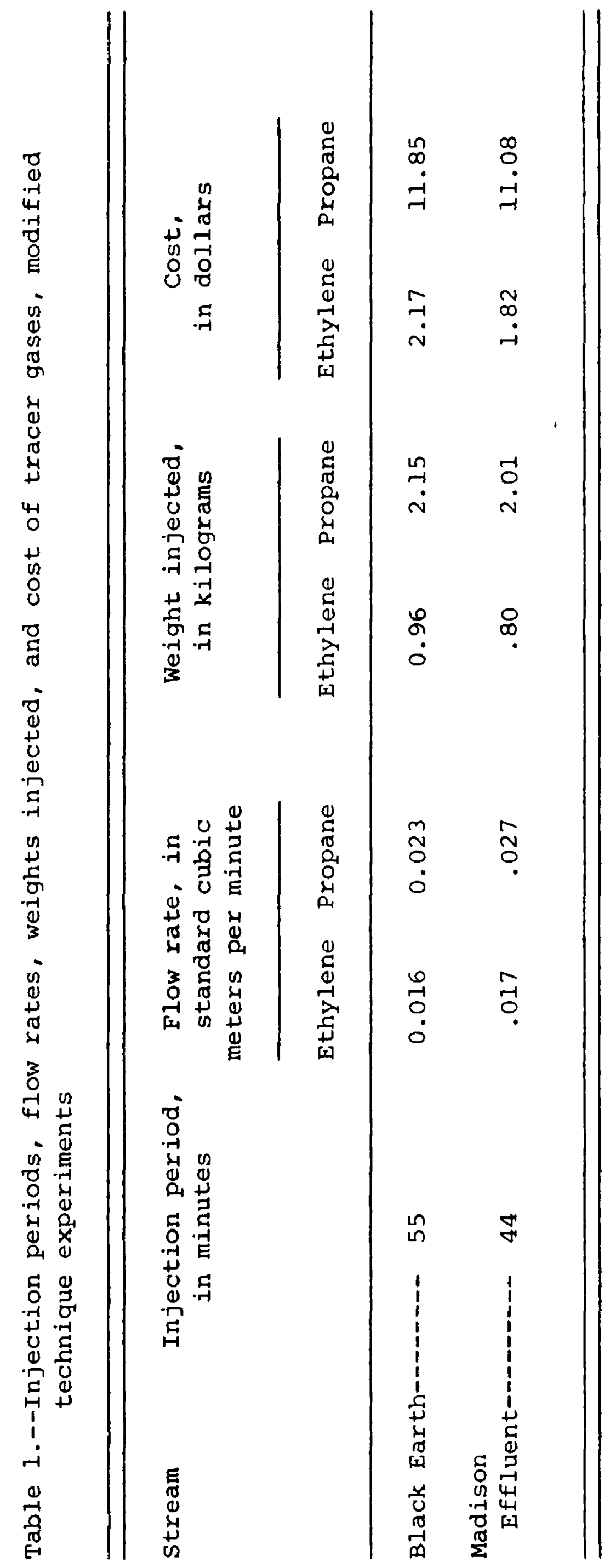


A rhodamine-WT dye in water solution was injected at the same injection point and for the same injection period as was used for the tracer gases. A Mariotte vessel was used to inject the dye solution. Details of the design and operation of a Mariotte vessel were presented by E. D. Cobb and J. F. Bailey (unpublished data, 1965). Dye injection rates and concentrations appropriate for the hydraulic conditions in Black Earth Creek and the Madison Effluent Channel were estimated using equations presented by E. D. Cobb and J. F. Bailey (unpublished data, 1965). A dye solution injection rate of $70 \mathrm{~mL} / \mathrm{min}$ was used for both streams; initial dye concentrations were $11.1 \times 10^{6}$ and $20.9 \times 10^{6} \mu \mathrm{g} / \mathrm{L}$ for Black Earth Creek and the Madison Effluent Channel, respectively.

One problem occurred in the injection of the propane in the Madison Effluent Channel experiment. The propane injection rate decreased during the latter stages of the injection period, despite attempts to maintain the rate by increasing the setting of the regulating value. The rapid flow and expansion through the valve apparently produced some freezing and a resultant restriction to the flow. A somewhat larger than normal flow rate was used in this experiment because the first cross section was closer to the injection point than usual. Thus, it was desired to get as much gas into the water in as short a time as possible. Similar problems with the propane system have occurred in other studies, although not as severe as in this experiment. To insure against such a problem, a two-cylinder system with a manifold for rapidly switching from one cylinder to the other could be used.

Sampling the tracers.--The first samples in the modified technique experiments were collected at cross-section 2 which was about 1 hour and 0.8 hour time of travel downstream from the tracer injection point for Black Earth Creek and the Madison Effluent Channel, respectively. This was to insure complete mixing of the tracers in the stream cross section. A Turner Model 111 fluorometer powered by a portable generator was used to determine when the dye had arrived at the cross section.

When the fluorometer indicated that the dye had arrived, samples were obtained from approximately the center of the flow. Samples for dye analysis were obtained in 32-mL polyseal-cap bottles. Each sample bottle was rinsed several times with the stream water before filling and capping. Samples for gas analysis were obtained in 60-mL glass bottles with ground-glass stoppers. A displacement-type sampler in which the bottle was flushed about three times with the stream water was used. One $\mathrm{mL}$ of reagent grade formalin solution was added to each bottle to prevent biological degradation during storage. Both the dye and gas samples were stored in a cool place out of the direct sunlight until return to the laboratory where they were stored in an incubator at $25^{\circ} \mathrm{C}$ until analysis.

Sampling was continued at cross-section 2 until sufficient samples were obtained to define the complete concentration-versus-time curves. The dye curve was used to correct for dye losses because rhodamine-WT is 
not a completely conservative tracer. In the modified technique, crosssection 2 is the first cross section at which samples are collected, and the measurements are referenced to this cross section. The reach between cross-section 2 and cross-section 1, the injection point, serves only as a zone where vertical and lateral mixing is accomplished.

In addition to collecting water samples for the determination of the concentrations of the gases and the dye, discharge measurements using a current meter and standard U.S. Geological Survey procedures (Buchanan and Somers, 1969) were made at cross-sections 2 and 4.

Analyzing the samples.--The concentrations of ethylene and propane in the water samples were determined using a gas chromatographic technique. The technique consists of introducing an aliquot of a water sample into a stripping chamber, stripping the ethylene and propane from the water with helium gas, trapping the ethylene and propane in a trap at the temperature of liquid nitrogen, warming the trap with hot water after the stripping process has been completed, and flushing the gases from the trap into a gas chromatograph equipped with a flame ionization detector. Details of the procedure have been presented by Shultz and others (1976).

Dye samples were analyzed with a Turner fluorometer and standard techniques described by E. D. Cobb and J. F. Bailey (unpublished data, 1965), Wilson (1968), and F. A. Kilpatrick, L. A. Martens, and J. F. Wilson (unpublished data, 1970).

Calculating the reaeration coefficients.--Two methods were used to calculate the reaeration coefficients from the results of the experiments, one based on the peak concentrations and the other based on the areas under the concentration-versus-time curves.

The peak concentration method has as its basis equation 2, however, this equation assumes that the dispersion-dilution tracer is conservative. To correct for losses of the rhodamine-WT dye, the following procedure is used.

$$
\begin{aligned}
& \text { Conservation of dye requires that } \\
& \qquad Q_{2} A_{2}=Q_{3} A_{3}=Q_{4} A_{4}
\end{aligned}
$$

where $Q$ is the water discharge; $A$ is the area under the dye concentrationversus-time curve; and the subscripts designate the cross sections. If there is dye loss, then $Q_{3} A_{3}$ and $Q_{4} A_{4}$ will be less than $Q_{2} A_{2}$. To correct for this loss, the procedure is to multiply each point of the dye concentration-versustime curves at cross-sections 3 and 4 by a correction factor to make equation 5 true. Equation 5 therefore becomes

$$
Q_{2} A_{2}=Q_{3} A_{3} J_{3}=Q_{4} A_{4} J_{4}
$$


where $J_{3}$ and $J_{4}$ are the correction factors. This correction procedure uses cross-section 2 as the reference cross section, for reasons discussed previously.

With the dye loss correction factors, equation 2 for reach 2-3 becomes

$$
K_{T_{2-3}}=\frac{1}{t_{3}-t_{2}} \log _{\mathrm{e}} \frac{\frac{C_{T_{2}}}{C_{D_{2}}}}{\frac{C_{T_{3}}}{C_{D_{3}{ }^{J}}}}
$$

and for reach $3-4$

$$
K_{T_{3-4}}=\frac{1}{t_{4}-t_{3}} \log _{e} \frac{\frac{C_{T_{3}}}{C_{D_{3}{ }^{J_{3}}}}}{\frac{C_{T_{4}}}{C_{D_{4}{ }^{J}}}}
$$

The area method has as its basis the equation

$$
K_{T}=\frac{1}{\bar{t}_{d}-\bar{t}_{u}} \log _{\mathrm{e}} \frac{A_{u}}{A_{d}}
$$

where $A$ is the area under the gas concentration-versus-time curve; $\bar{t}$ is the time of travel of the centroid of the gas tracer mass; and the $u$ and $d$ subscripts indicate the upstream and downstream ends of the reach, respectively. If there is flow accrual, then the areas must be corrected and equation 9 becomes

$$
K_{T}=\frac{1}{\bar{t}_{d}-\bar{t}_{u}} \log _{\mathrm{e}} \frac{A_{u} Q_{u}}{A_{d}{ }^{Q}}
$$

The times of travel of the centroids of the tracer masses in equations 9 and 10 are defined by the equation

$$
\bar{t}=\frac{\int t c(t) d t}{\int c(t) d t}
$$

where $C(t)$ is the concentration of tracer at time $t$ and the denominator is $A$, the area under the gas concentration-versus-time curve. These integrals were evaluated using the trapezoid procedure. The upper limit of integration for both integrals was taken as the time at which the peak concentration had decreased to 1.0 percent of the maximum concentration, as was done by Yotsukura, Fischer, and Sayre (1970). 
The area method defined by equation 9 has the advantage that computation of the tracer gas desorption coefficient is independent of measurements of the dye concentrations. Therefore, possible dye losses do not affect the area method determinations of the desorption coefficient. However, the area method must assume that no significant quantities of gas are lost from the gas tracer mass as a result of entrapment in dead-water zones.

The tracer gas desorption coefficients for ethylene and propane determined from equations 7,8 , and 10 are converted to reaeration coefficients with the equations

$$
\begin{aligned}
& K_{2}=1.15 K_{E} \\
& K_{2}=1.39 K_{P}
\end{aligned}
$$

where the $E$ and $P$ subscripts indicate the ethylene and propane tracer gases, respectively. Details of the development of these equations were presented by Rathbun and others (1978).

\section{RESULTS}

Radioactive Technique

Results of the radioactive tracer studies were evaluated by considering the following:

(1) Tracer concentrations at the downstream end of the study reach;

(2) percentage change of the krypton/tritium ratio through each reach; and

(3) liquid scintillation counting statistics.

Evaluation of these criteria indicated excellent results for both streams and that almost ideal radioactive tracer studies were conducted. Discussion of the evaluations of these three criteria are presented in the following paragraphs.

At the downstream end of each stream segment, there must be sufficient tracer material left so that an accurate reaeration coefficient can be computed for that segment. Samples taken at cross-section 4 on Black Earth Creek showed that radioactive disintegrations attributable to the tritium tracer were 3.5 times that of the background sample for that cross section and 4.8 times for the krypton-85. Similarly, for cross-section 4 of the Madison Effluent Channel, the tritium count was 3.2 times the background and the krypton-85 count 5.3 times. These levels of activity are sufficiently high to permit accurate determination of the radioactive tracer concentrations at these cross sections. It is apparent, therefore, that the upstream cross sections also had more than adequate radioactive tracer concentrations. Fluorescent dye concentrations were more than adequate at all sampling cross sections also. 
The second criterion required for an accurate tracer measurement of a stream reaeration coefficient for a given stream segment is sufficient gas loss to the atmosphere between the sampling cross sections. Gas loss must be large compared with experimental errors inherent in the determination of the tracer concentrations. Gas loss was evaluated using the percentage change in the krypton/tritium ratio through each reach. The ratios for reaches 1-2, 2-3, and 3-4 of Black Earth Creek. changed $30.3,63.7$, and 53.0 percent, respectively. Similarly, the ratios for reaches 1-2, 2-3, and 3-4 of the Madison Effluent Channel changed $3.6,19.0$, and 51.5 percent, respectively. The ratio change for reach 1-2 of the Madison Effluent Channel is considerably smaller than desired, and the change for reach $2-3$ is marginally adequate; all the other ratios changes are adequate for the accurate computation of stream reaeration coefficients. Reaches 1-2 are, however, not of importance in the present comparison studies because the modified tracer technique does not provide measured reaeration coefficients for these reaches.

The third criterion required for an accurate radioactive tracer study is good scintillation counting statistics. Disintegrations of radioisotopes are random by nature, the rate of particle emissions varying from one second to the next. Therefore, counting time must be of sufficient duration that a sufficient number of disintegrations be observed to determine an accurate mean level of activity for each stream sample. Laboratory and counting procedures used in this study were identical to those established by Tsivoglou and Wallace (1972). Three samples at the peak of the dye concentration curve for each sampling cross section were selected for analysis, and three replicate scintillation counting vials were prepared from each of these samples. Each of these nine sample vials was counted four times for a 10-minute period, giving a total of 6 hours counting time for each sampling cross section on each stream. Minimum counts were recorded at cross-section 4 on each stream. For cross-section 4 on the Madison Effluent Channel, total tritium and krypton-85 counts were 23,800 and 61,300 , respectively. For cross-section 4 on Black Earth Creek, the counts were 39,700 and 59,400, respectively. Thus, the number of counts was more than adequate. Deviations of individual vial counts from the mean for a given stream sample were small. The largest deviations occurred for the samples from cross-section 4 on each stream, as would be expected. For Black Earth Creek, the maximum vial count deviation from the mean of the 36 vial counts was 6.3 percent for tritium and 8.9 percent for krypton-85. For the Madison Effluent Channel, these deviations were 9.5 and 9.3 percent, respectively. Thus, based upon levels and variations in activity, it is concluded that the scintillation counting statistics were very good for both studies.

Radiotracer data, including the dose quantities, the krypton/tritium ratios at the upstream and downstream end of each reach, and the krypton and tritium concentrations at the downstream end of each reach are presented in table 2. The dose quantities were determined at the reactor facility where the dose mixtures were prepared, and are approximate 


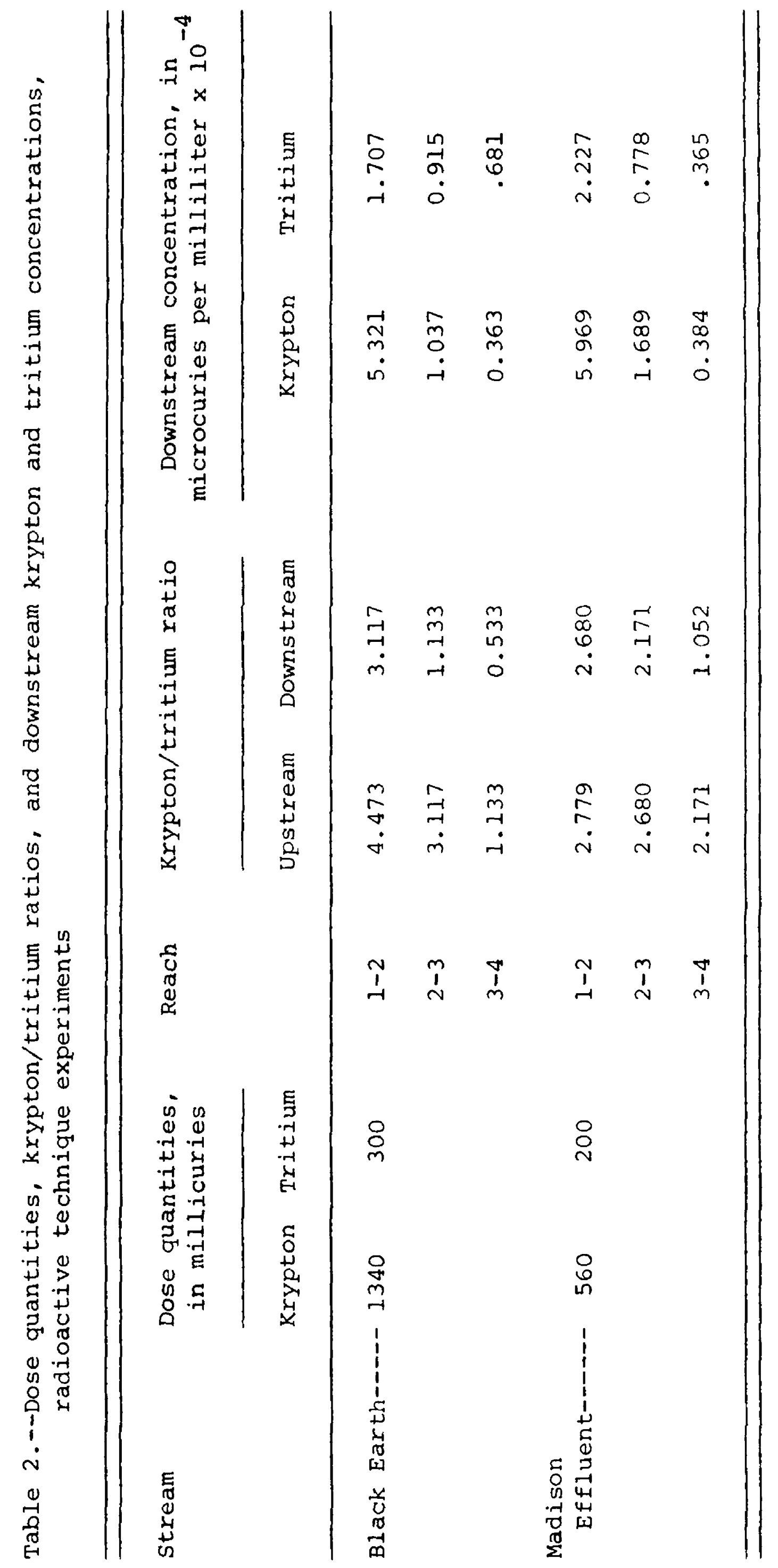


only. This explains why the krypton/tritium ratio at the upstream end of reach 1-2 of Black Earth Creek is very slightly larger than the krypton/tritium ratio for the dose mixture. Reaeration coefficients computed with equations 3 and 4 , the times of travel, and the krypton/tritium ratios are presented in table 3 together with the average water temperatures. For convenience in comparing the reaeration coefficients, they were adjusted to a common temperature of $20^{\circ} \mathrm{C}$ with the equation

$$
K_{20}=K_{2}(1.0241)(20-\tau)
$$

where $\tau$ is the water temperature in ${ }^{\circ} \mathrm{C}$ and the 1.0241 factor was determined by Elmore and West (1961). The coefficients at $20^{\circ} \mathrm{C}$ are presented in table 3 also.

\section{Modified Technique}

The ethylene and propane concentrations as a function of time at crosssections 2 and 3 for the Black Earth Creek experiment are presented in figures 11 and 12, respectively. The ethylene and propane concentrations at cross-section 4 are presented in figures 13 and 14 , respectively. The dye concentrations as a function of time at cross-sections 2, 3, and 4 are presented in figures 15,16 , and 17 , respectively.

The ethylene and propane concentrations as a function of time at crosssections 2, 3, and 4 for the Madison Effluent Channel experiment are presented in figures 18, 19, and 20, respectively. The dye concentrations as a function of time at cross-sections 2, 3, and 4 are presented in figures 21,22 , and 23, respectively.

Peak concentrations and peak times determined from the curves presented in figures 11 through 23 are presented in table 4. The peak concentrations for the propane tracer in the Madison Effluent channel experiment, however, cannot be used to compute reaeration coefficients because of the injection problem previously discussed. A plateau was obtained at cross-section 2, and therefore, this concentration is accurately known. However, because this plateau concentration was not maintained for the same length of time as the dye, the peak propane concentrations at cross-sections 3 and 4 were less than they would have been, had the proper flow rate been maintained.

The areas under the curves presented in figures 11 through 23 , and the centroids of the areas were determined using the trapezoid rule and the results are presented in table 5 .

The measured water discharges at cross-sections 2 and 4 for the Black Earth Creek experiment were 1.07 and $1.12 \mathrm{~m}^{3} / \mathrm{s}$, respectively. The discharge at cross-section 3 was estimated to be $1.10 \mathrm{~m}^{3} / \mathrm{s}$, based on these measured discharges and the times of travel through reaches 2-3 and 3-4. From these discharges, the areas of the dye curves presented in table 5 and equation 6 , the dye correction factors $J_{3}$ and $J_{4}$ were calculated to be 1.112 and 1.160 , respectively. 


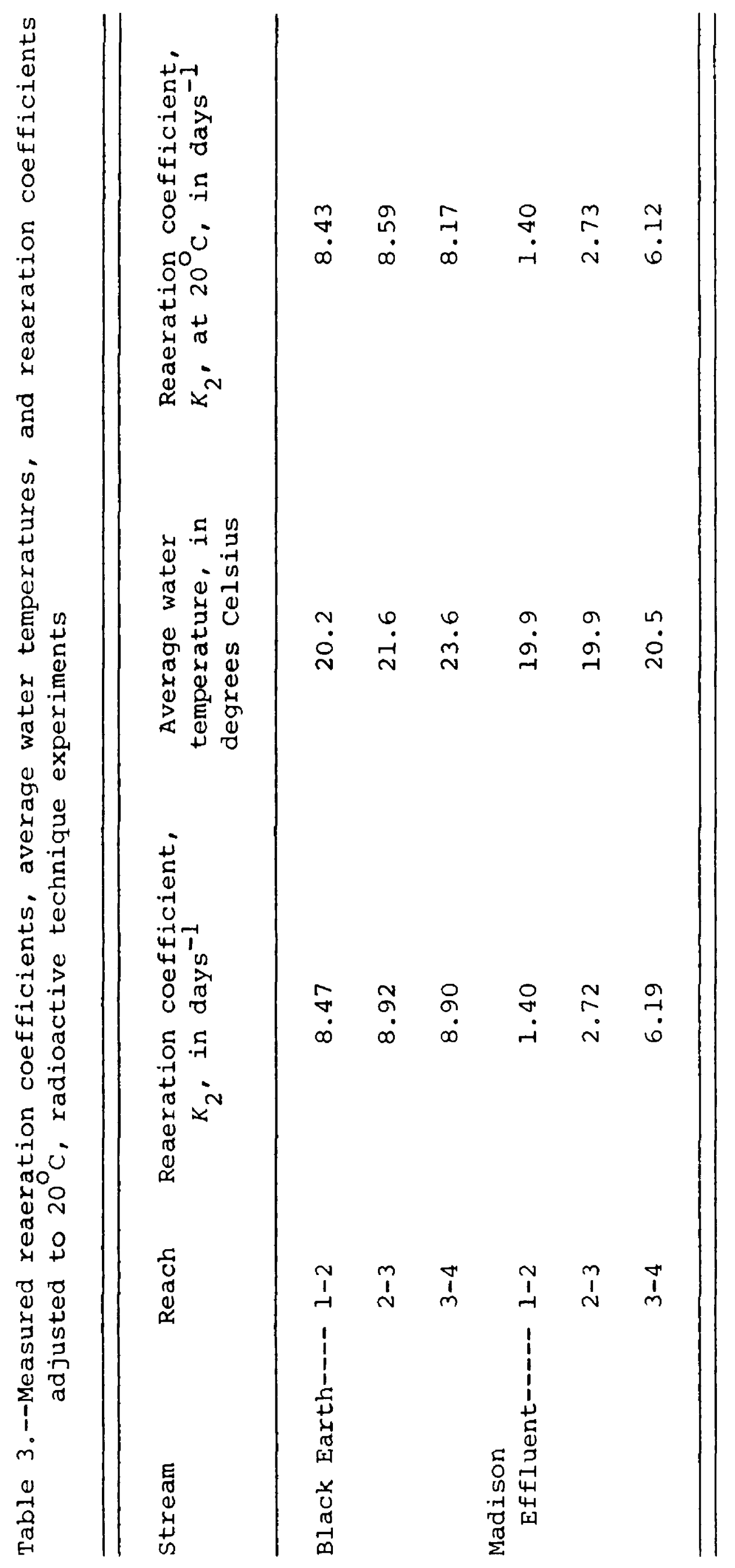




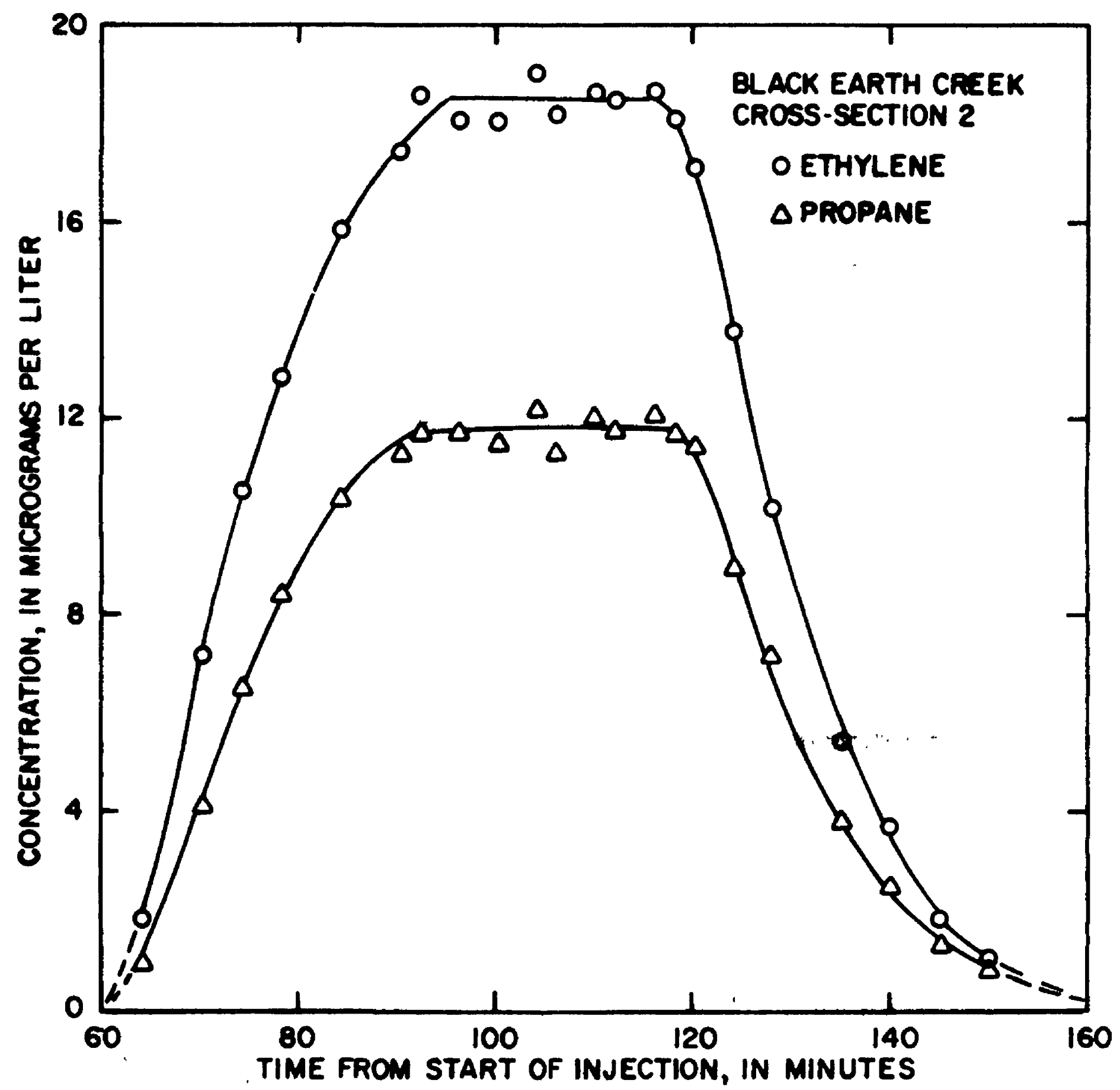

Figure 11.--Concentrations of ethylene and propane as a function of time at cross-section 2, Black Earth Creek. 


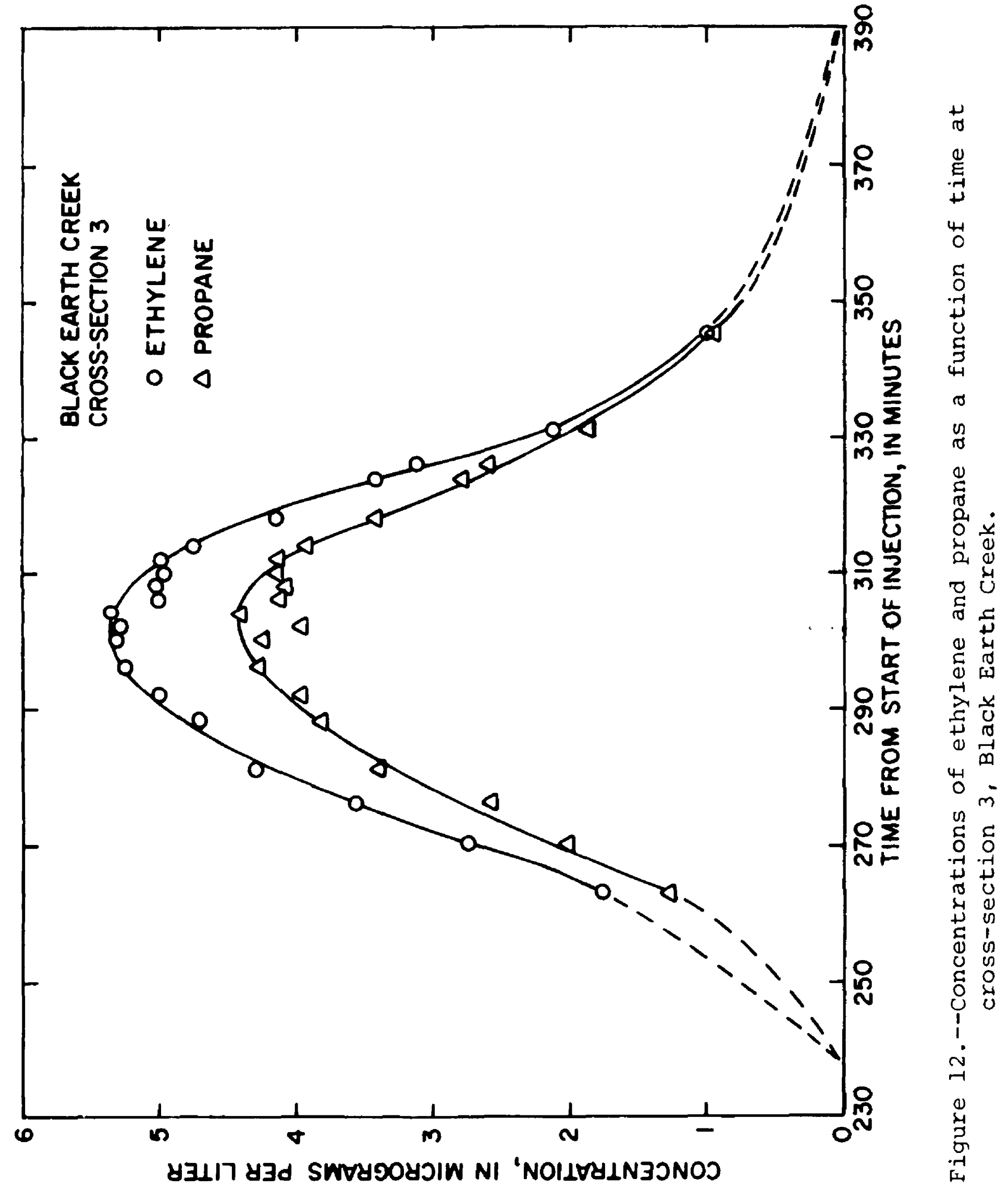




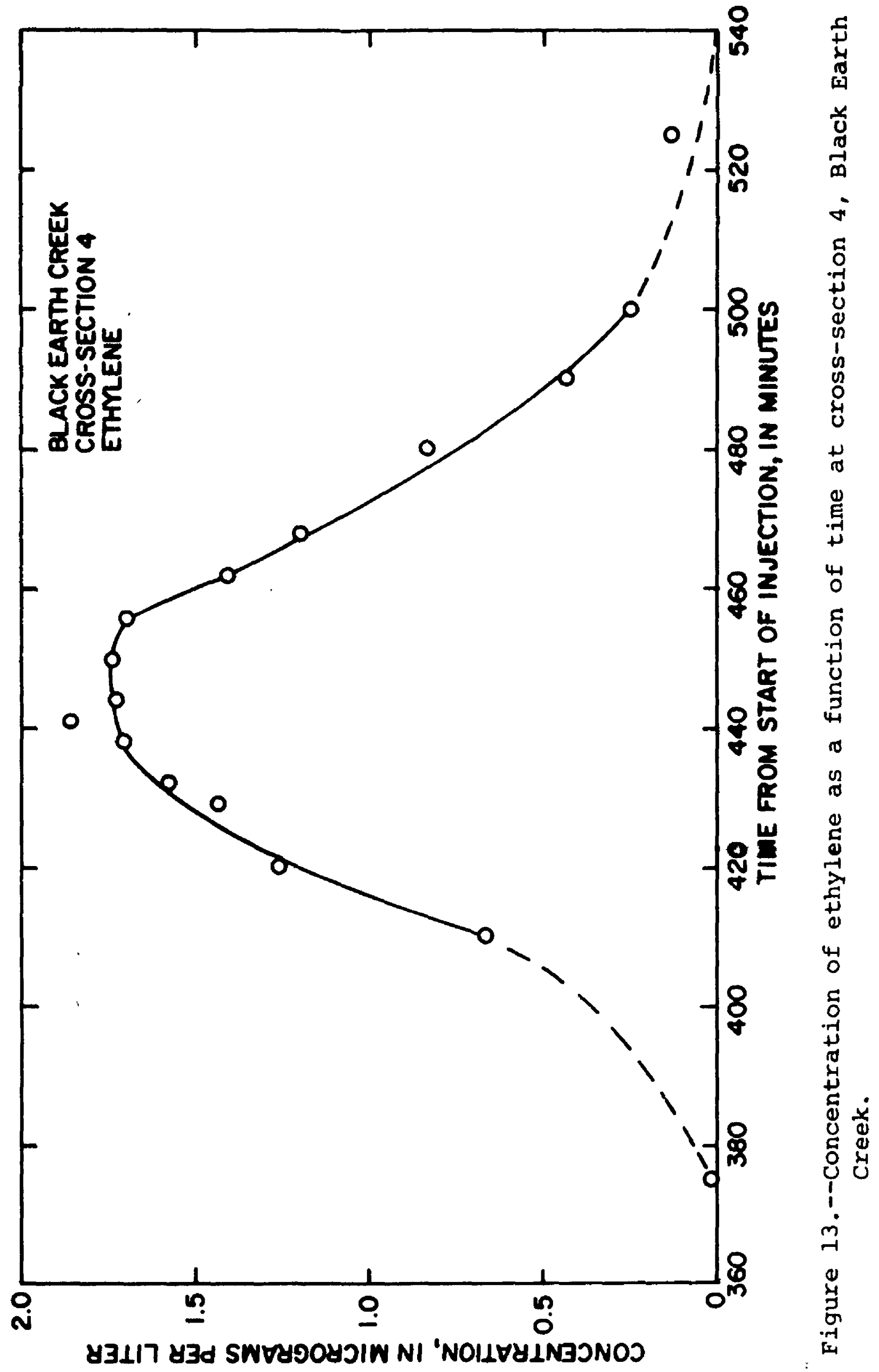




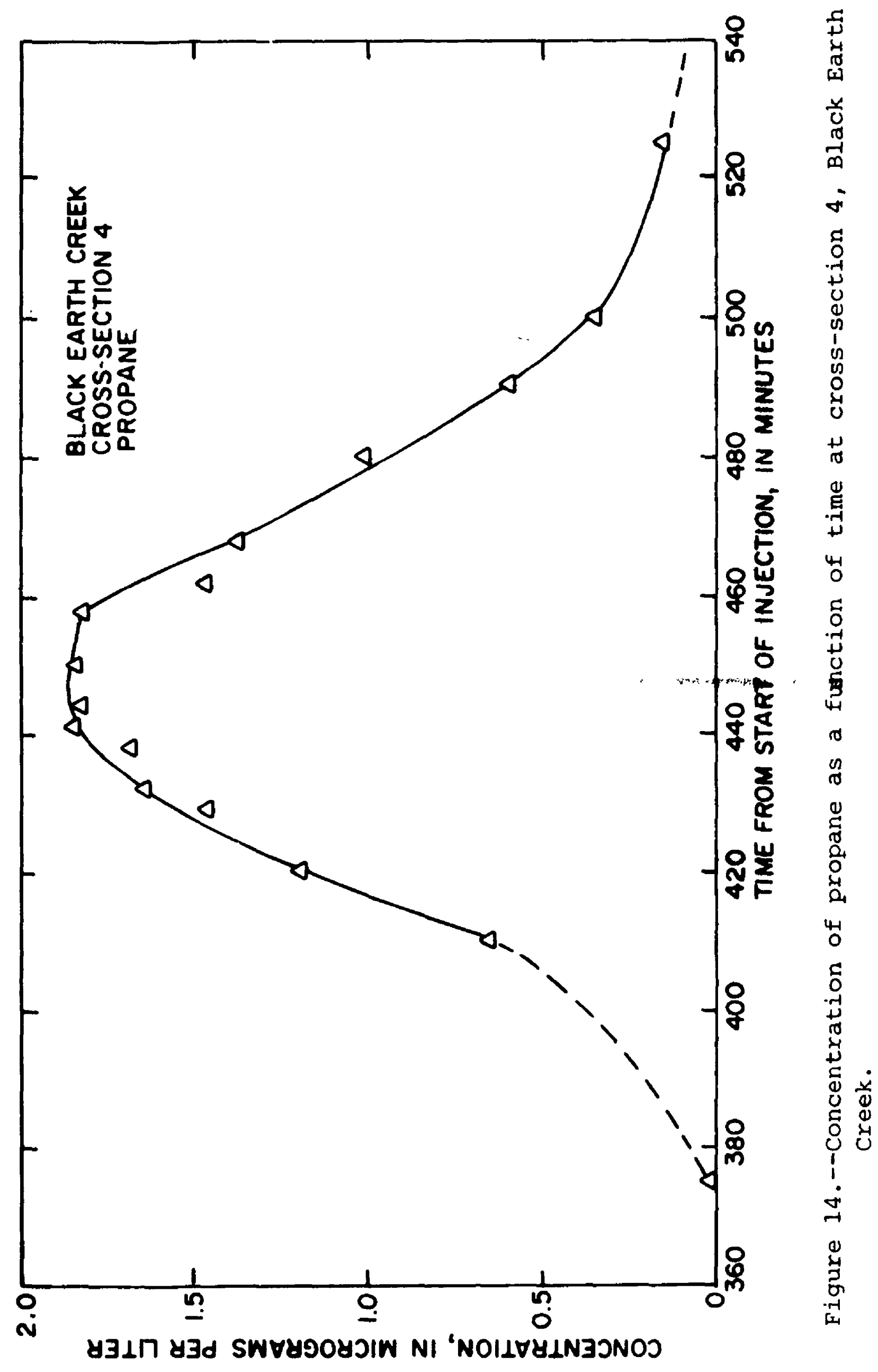




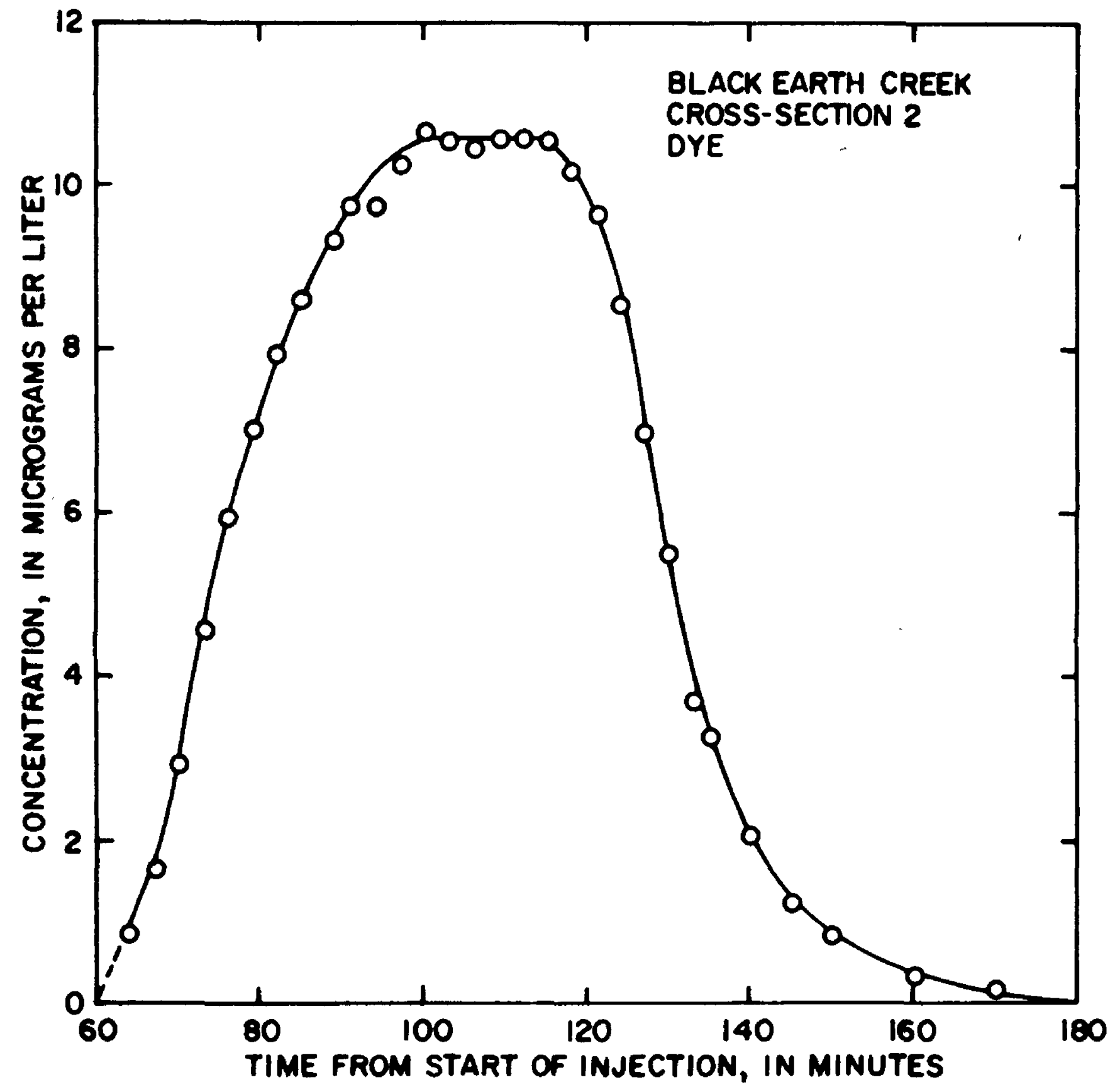

Figure 15.--Concentration of rhodamine-WT dye as a function of time at cross-section 2, Black Earth Creek. 


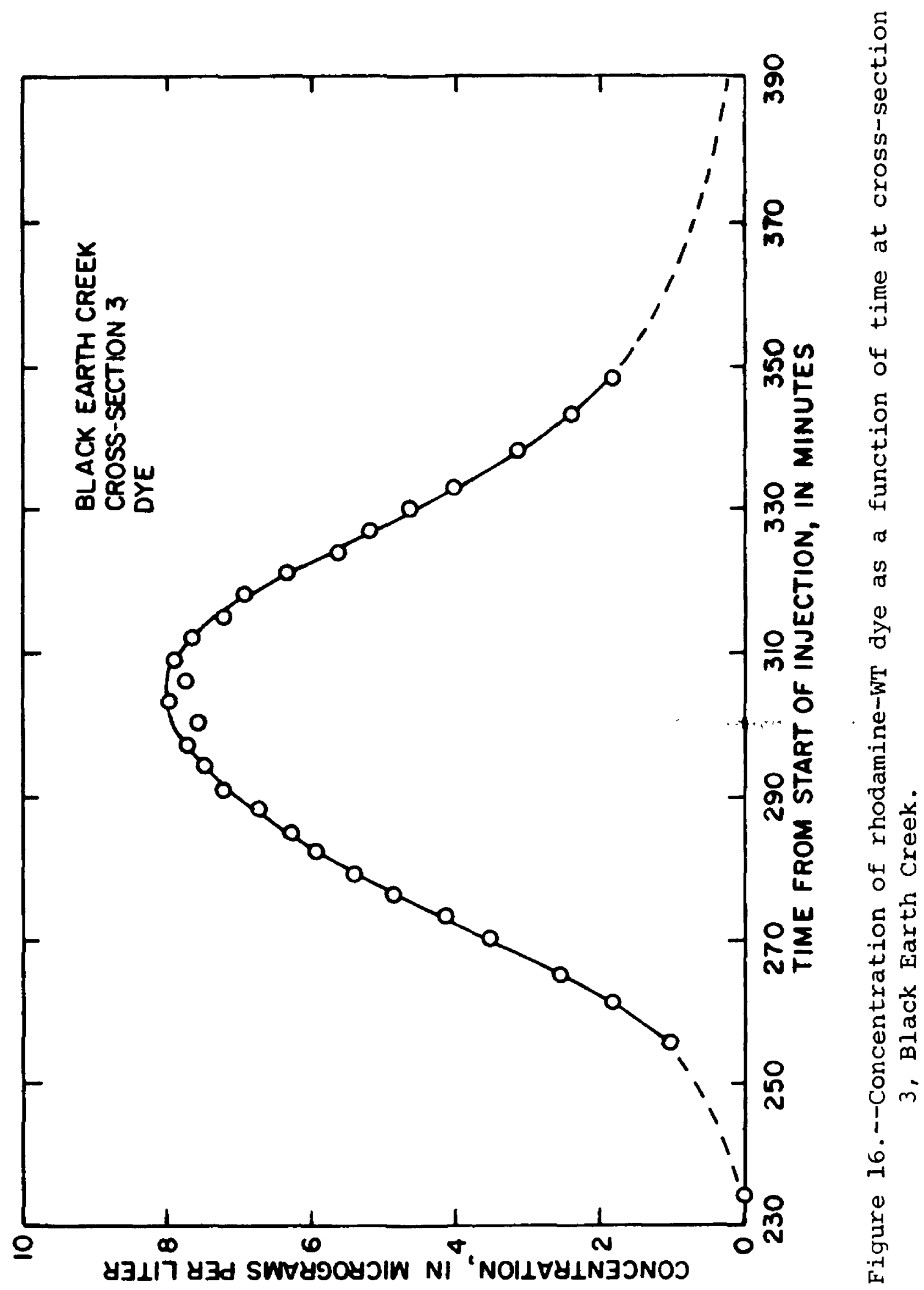




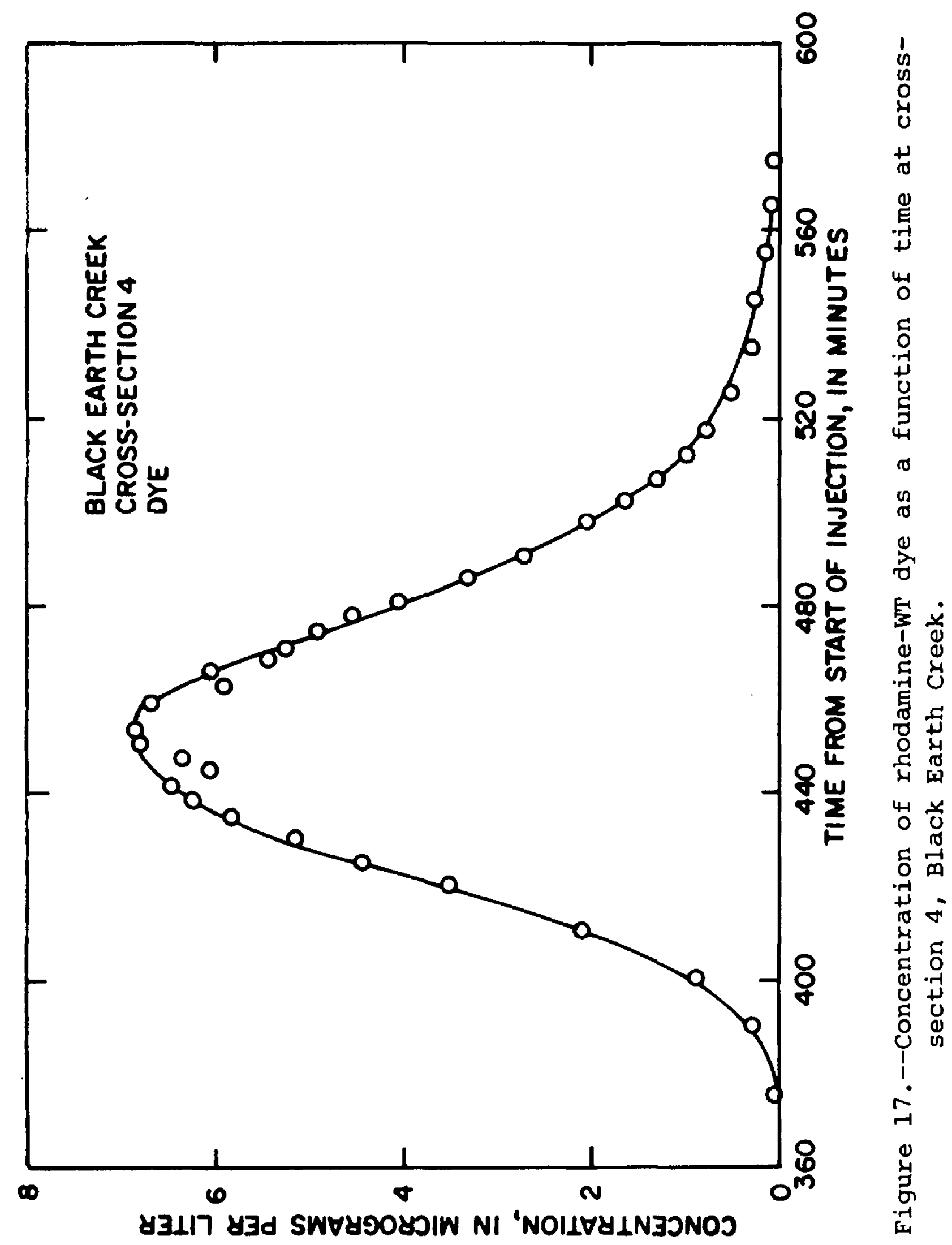




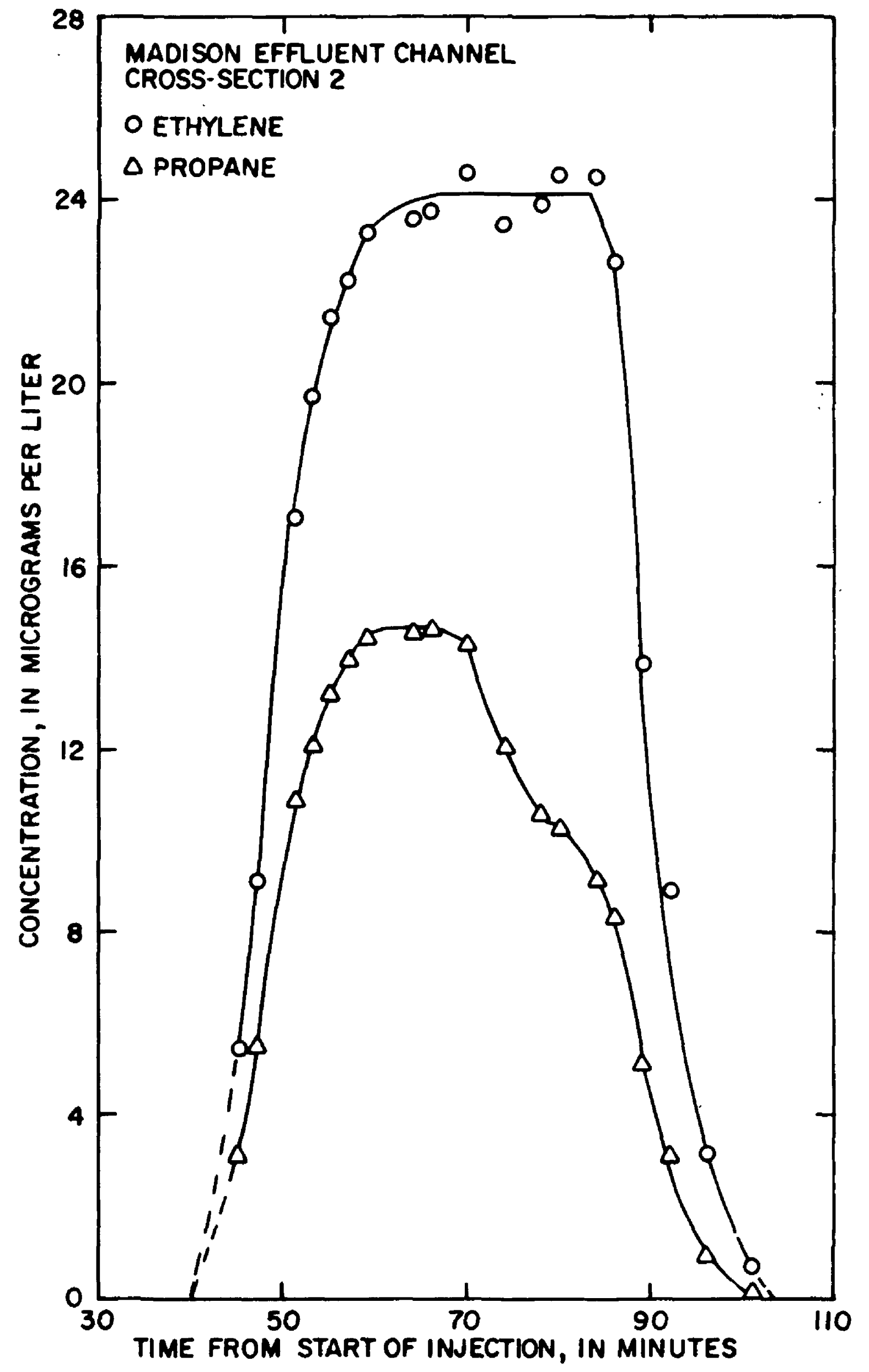

Figure 18.--Concentrations of ethylene and propane as a function of time at cross-section 2, Madison Effluent Channel. 


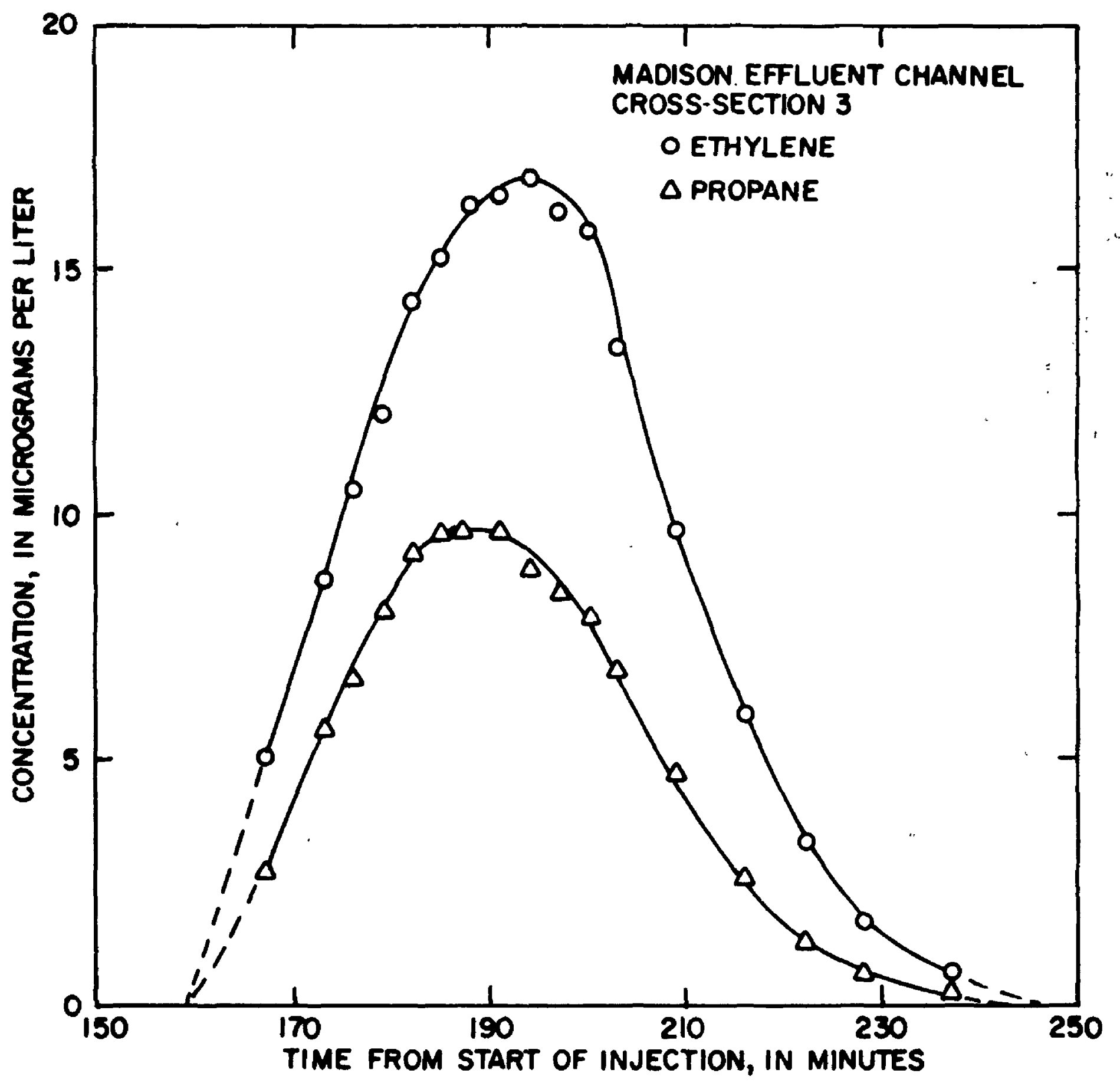

Figure 19.--Concentrations of ethylene and propane as a function of time at cross-section 3, Madison Effluent Channel. 


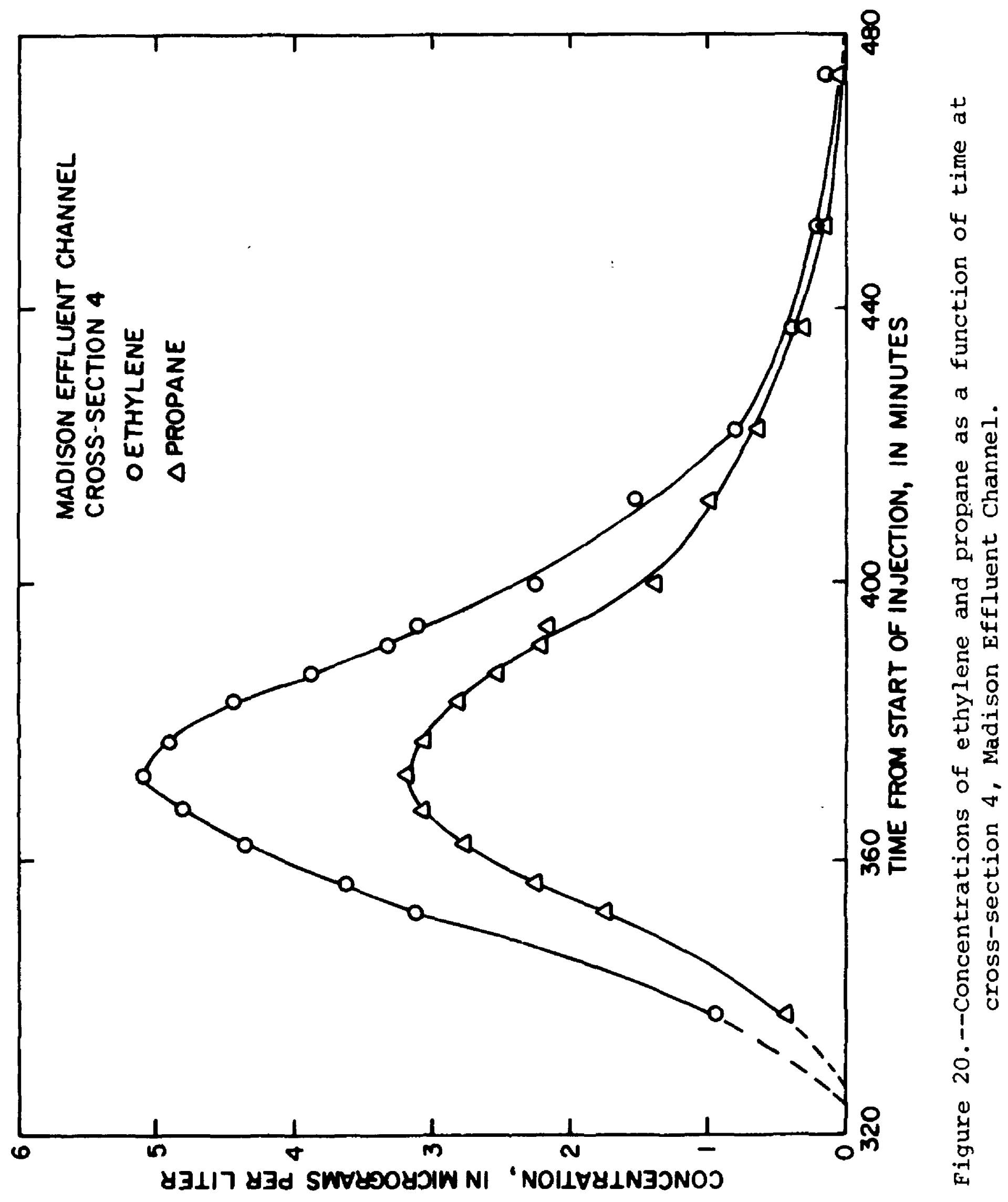




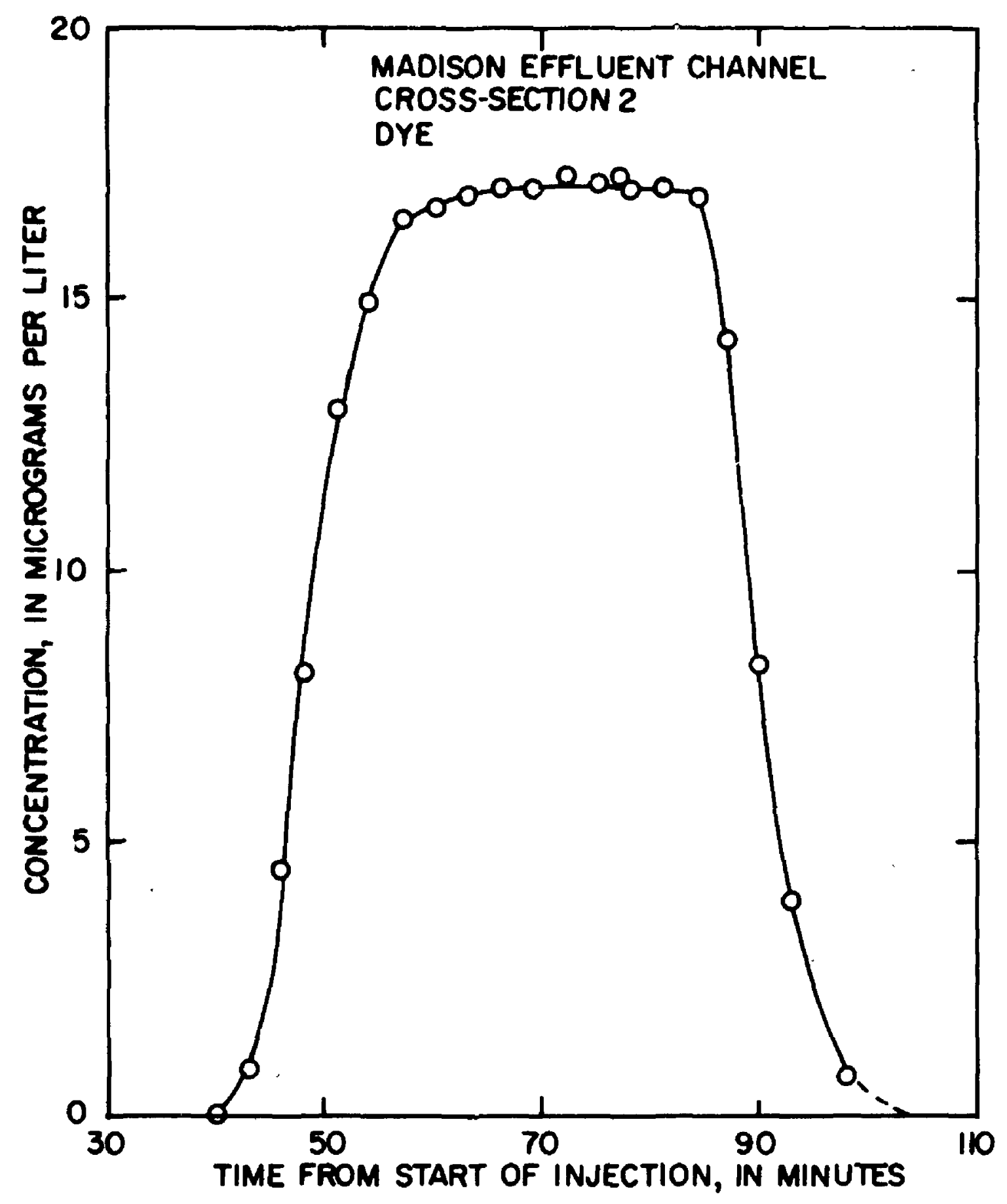

Figure 21.--Concentration of rhodamine-WT dye as a function of time at cross-section 2, Madison Effluent Channel. 


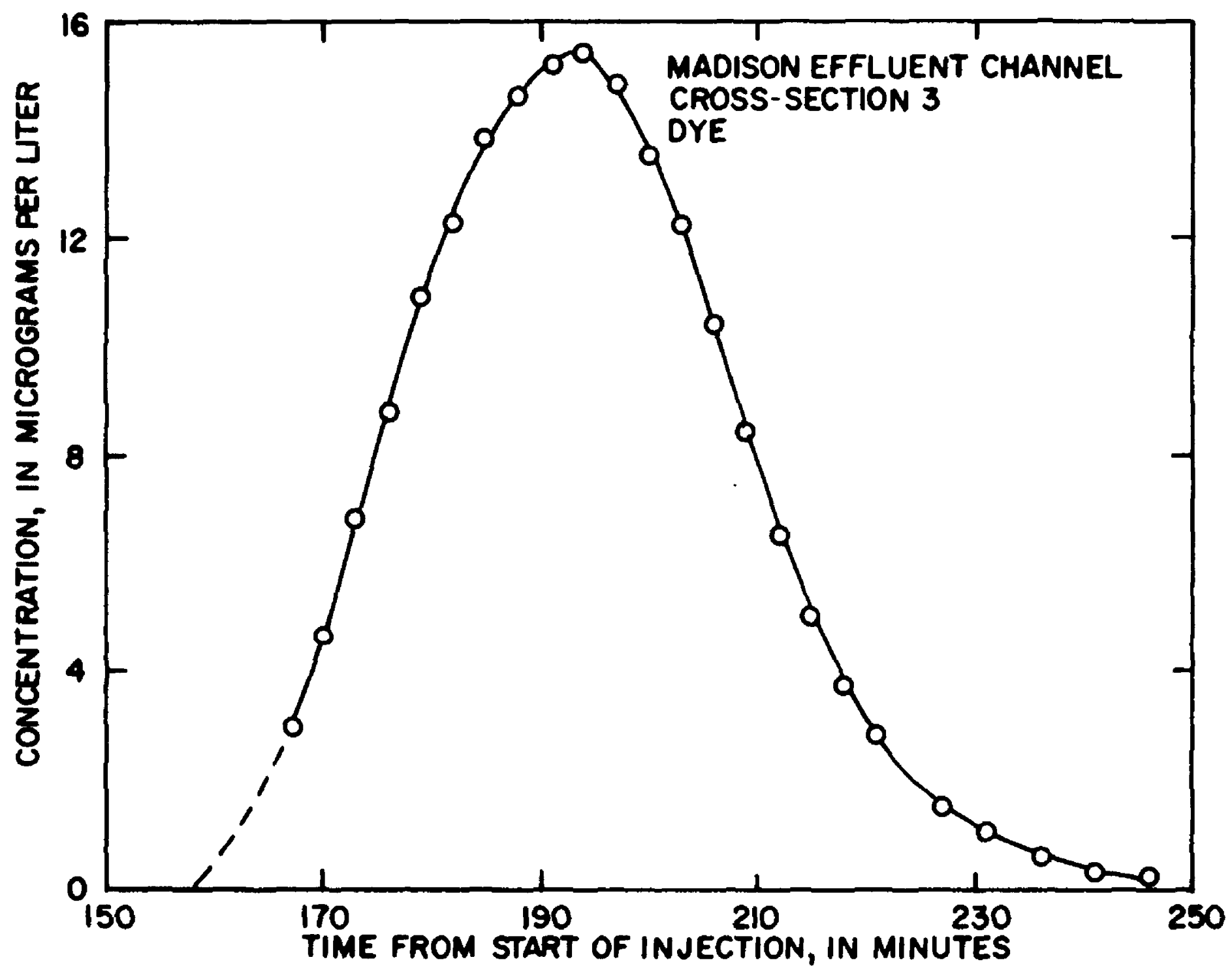

Figure 22.--Concentration of rhodamine-WT dye as a function of time at cross-section 3, Madison Effluent Channel. 


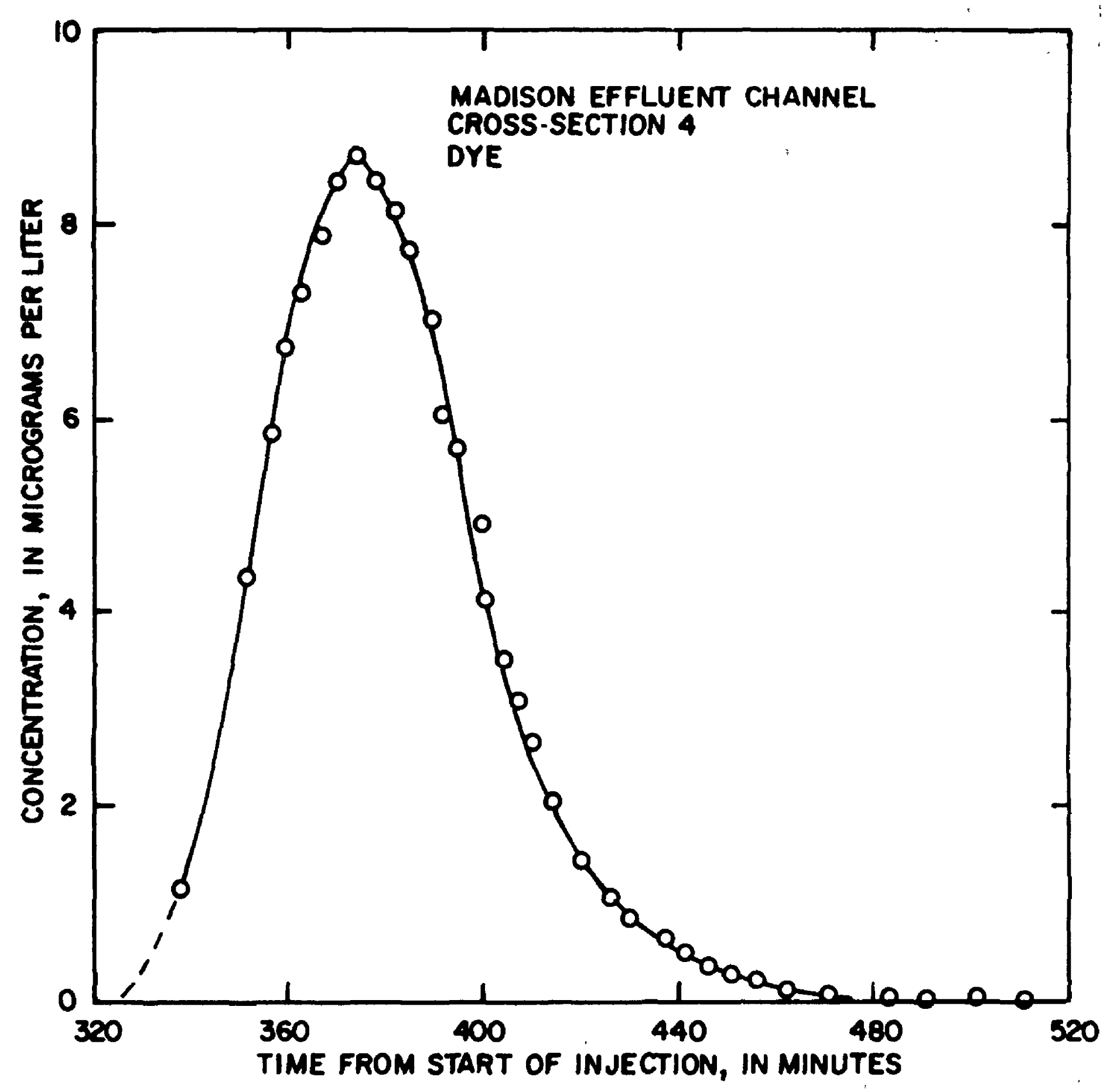

Figure 23.--Concentration of rhodamine-WT dye as a function of time at cross-section 4, Madison Effluent Channel. 


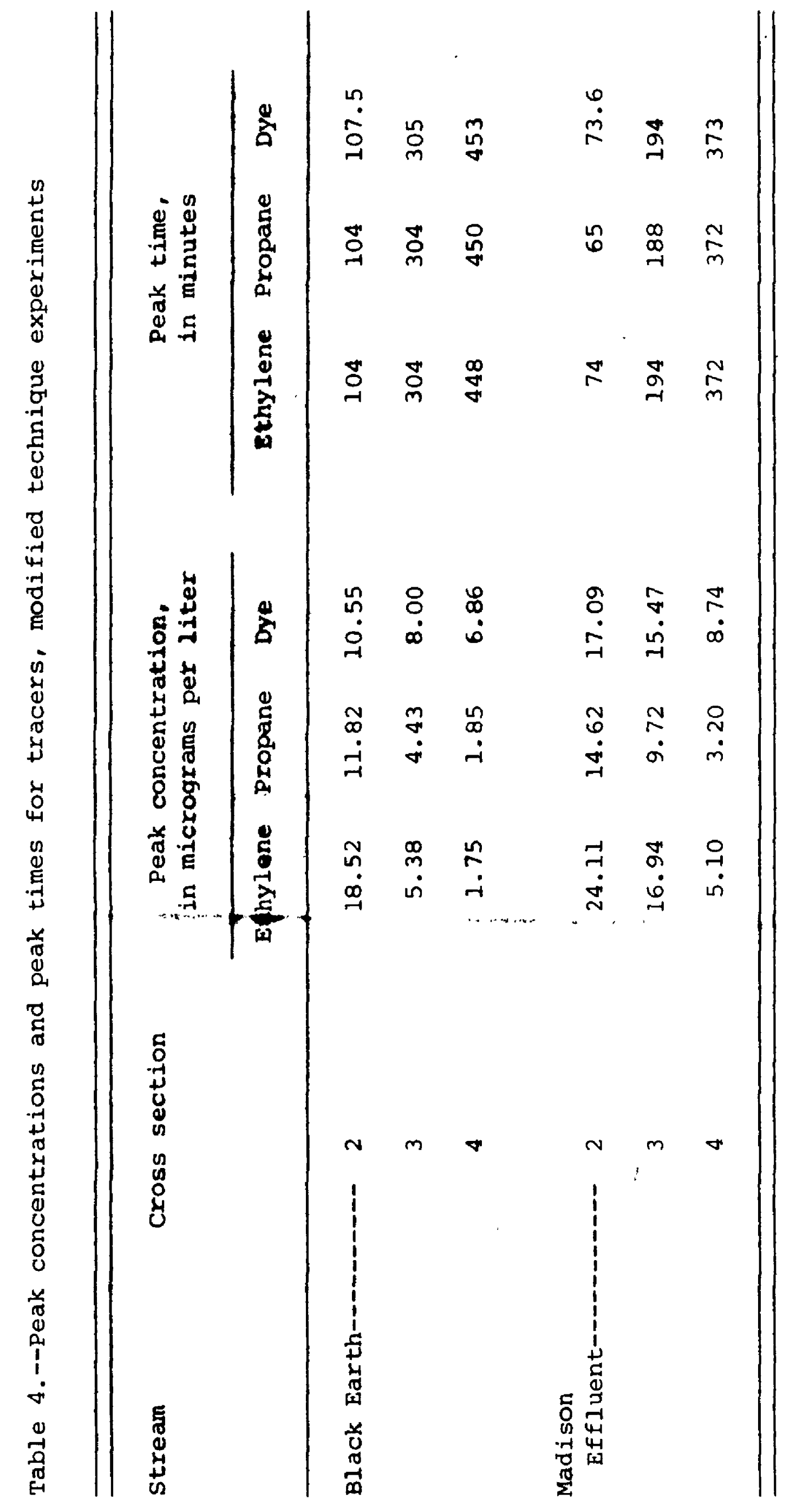




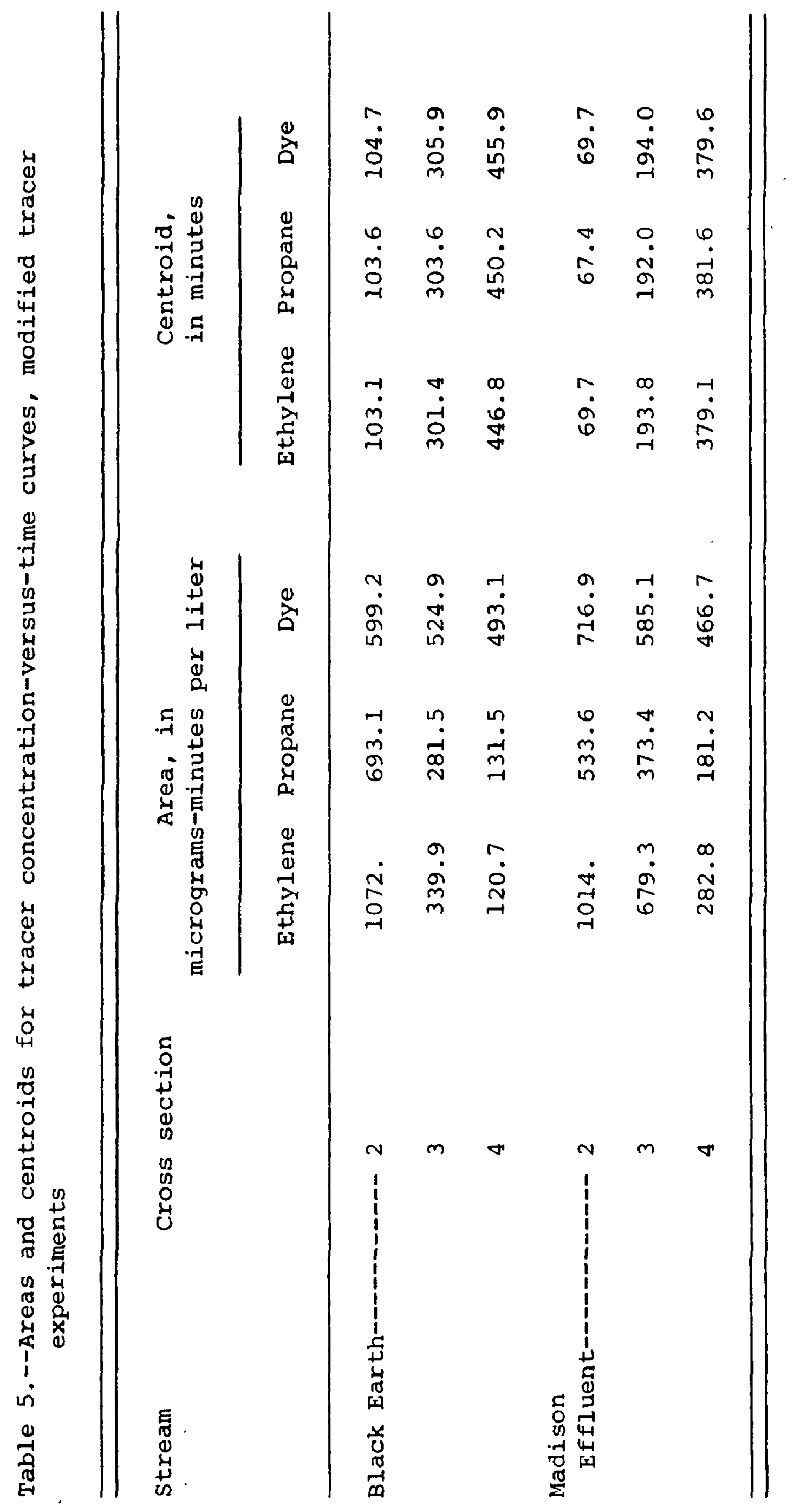


The determination of the dye corrections factors for the Madison Effluent Channel experiment was complicated by an unsteady flow condition. Because both techniques use rhodamine-WT dye and because different types of injection processes are used, it was necessary to initiate the modified technique injection some time period after the injection of the radioactive tracers. This was to insure that the leading edge of the dye used in the modified technique did not overtake the trailing edge of the dye used in the radioactive technique. Therefore, there was a 2-hour lag period between the experiments.

Unfortunately, the discharge increased about 40 percent during this lag period, and this increase is shown in table 6 by the times of travel determined from the peak times of the dye curves. Water discharge measurements were made at cross-sections 2 and 4 , however, these were not at the same time that the modified technique tracers were passing these cross sections. Thus, there was insufficient information to permit determination of how much of the reduction of the area under the dye curves at cross-sections 3 and 4 was the result of dye loss and how much was the result of the increase in discharge.

To estimate the dye correction factors and the water discharges at cross-sections 3 and 4 , three assumptions were necessary. First, it was assumed that the water discharge at cross-section 2 could be calculated from the dye plateau concentration at cross-section 2, the concentration of the dye injected, and the injection rate. This is a standard procedure for the measurement of discharge by a dye dilution method, and details of the method are presented by E. D. Cobb and J. F. Bailey (unpublished data, 1965). Consideration of figure 21 shows that the plateau was of about 21 minutes duration, therefore, the plateau concentration could be accurately determined. Also the concentration did not seem to be changing with time, suggesting that the discharge had not yet begun to increase significantly or that the change was occurring slowly. Using this procedure, the water discharge at cross-section 2 was calculated to be $1.42 \mathrm{~m}^{3} / \mathrm{s}$.

Second, it was assumed that dye loss in a reach was proportional to the time of travel through the reach. Dye loss is believed to be the result of photochemical decay and adsorption on suspended sediment, bottom materials, and vegetation. Because these processes are all dependent on exposure time, the assumption of dependence on time of travel should be reasonable.

Third, it was assumed that the dependence of the dye loss on time of travel for the Madison Effluent Channel was the same as that observed in Black Earth Creek. Some factors support this assumption, others do not. The two streams are in the same geographical area, and therefore, the types of soil in the banks and bottoms of the streams could be similar. The experiments were conducted on consecutive days and sunlight conditions were qualitatively the same. On the other hand, as discussed previously, the channel characteristics and water quality characteristics were different in many respects. 
Table 6.--Time of travel for the Madison Effluent Channel experiments, as determined from the dye peak times

\begin{tabular}{ccc}
\hline Reach & Time of travel, in minutes \\
\cline { 2 - 2 } & Radioactive & Modified \\
\hline $2-3$ & 134 & 120 \\
$3-4$ & 203 & 179 \\
\hline
\end{tabular}


The dye correction factor was assumed to depend on time of travel according to

$$
J=a t_{p}^{b}
$$

where $t$ is the time-of-travel of the peak dye concentration. Using the calculated values of $J_{3}$ and $J_{4}$, a value of 1.00 for $J_{2}$, and the peak times of travel for the Black Earth Creek experiment, the constants a and $b$ were determined by linear regression analysis to be 0.618 and 0.103 , respectively. Using these constants, equation 15, and the peak times of travel from the Madison Effluent Channel experiment, $J_{3}$ and $J_{4}$ were calculated to be 1.062 and 1.136 , respectively. Using these J factors, the areas presented in table 5 and equation 6 , the discharges at cross-sections 3 and 4 were computed to be 1.64 and $1.92 \mathrm{~m}^{3} / \mathrm{s}$, respectively.

These dye correction factors appear to be reasonable values for a stream of the type of the Madison Effluent Channel. Also the water discharges computed from these factors were within the range of the discharges measured at cross-sections 2 and 4 . These measured discharges determined by two crews at about the time the modified technique tracers were passing through cross-section 3 were 2.00 and $1.41 \mathrm{~m}^{3} / \mathrm{s}$ at cross-sections 2 and 4 , respectively. Thus, the estimation procedure based on the three assumptions gives reasonable values for both the dye correction factors and the water discharges.

A 3-hour lag period between the experiments was used on Black Earth creek. The longer lag period was used because the time of travel through the study section was longer than for the Madison Effluent Channel section. Also Black Earth Creek, as discussed previously, is a pooland-riffle stream with a number of bends, and therefore, there was a greater tendency for the tracers to disperse Iongitudinally than for the Madison Effluent Channel. The times of travel, determined from the peak times of the dye curves, are presented in table 7. Comparison of the results shows that there was very little difference in the travel times for the radioactive and modified technique experiments, suggesting that the hydraulic conditions in the stream for the two experiments were the same.

The peak concentrations and peak times presented in table 4 were used with the dye correction factors and equations 7, 8, 12, and 13 to calculate reaeration coefficients by the peak method. The areas and centroids presented in table 5 and the water discharges were used with equations 10,12 , and 13 to calculate reaeration coefficients by the area method. The reaeration coefficients and the average reach water temperatures are presented in table 8 .

\section{Comparison of Reaeration Coefficients}

The experimental reaeration coefficients were adjusted to $20^{\circ} \mathrm{C}$ using equation 14 and the average reach water temperatures. The results 
Table 7.--Time of travel for the Black Earth Creek experiments, as determined from the dye peak times

\begin{tabular}{lcc}
\hline Reach & Time of travel, in minutes \\
\hline $2-3$ & Radioactive & Modified \\
$3-4$ & 197 & 198 \\
\hline
\end{tabular}




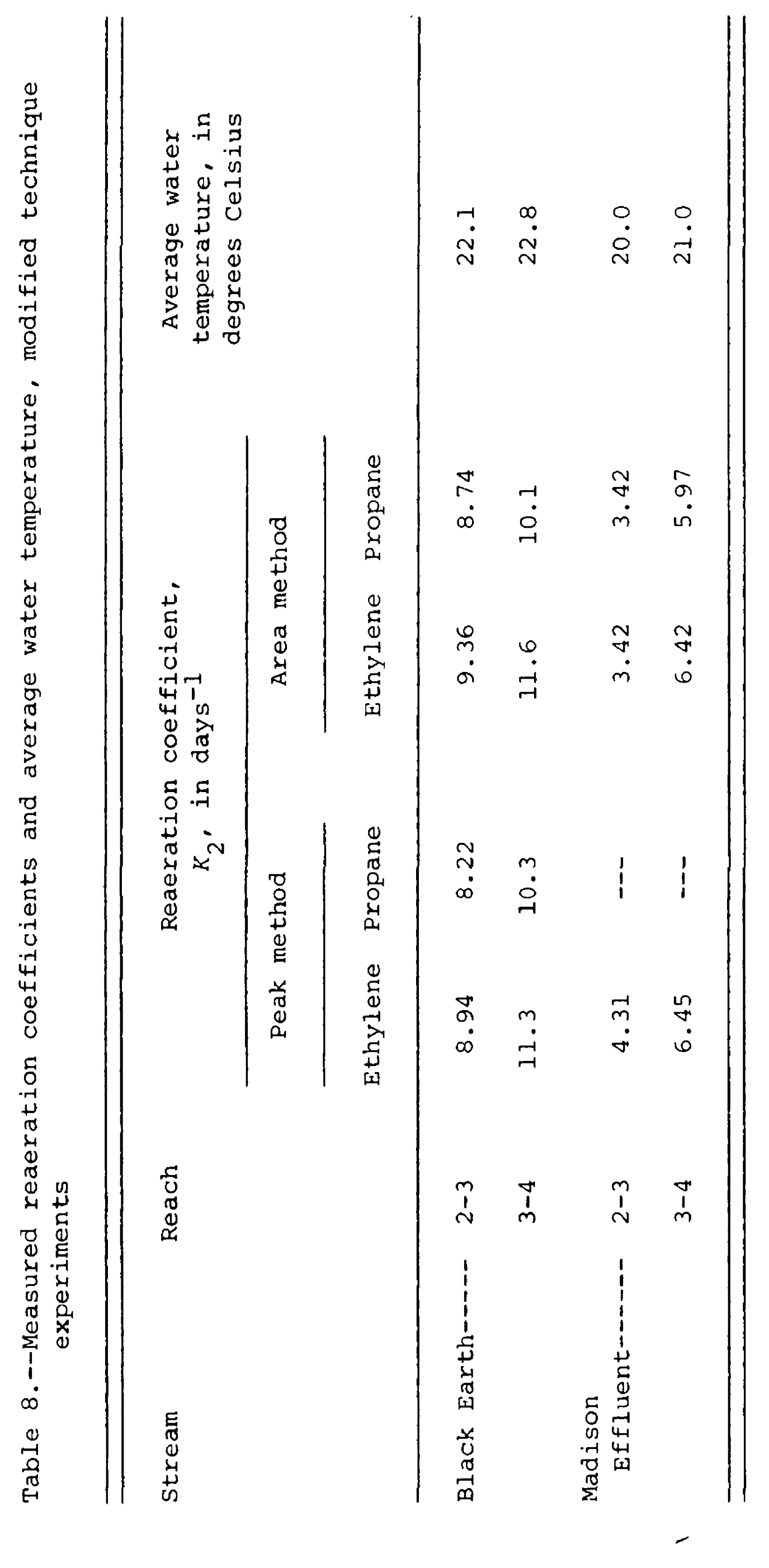


are presented in table 9. To facilitate comparison of the results, the radioactive technique coefficients at $20^{\circ} \mathrm{C}$ presented previously in table 3 are presented in table 9 also.

Percentage differences defined as

$$
\text { Percentage difference }=\frac{K_{2}{ }_{\text {Mod }}-K_{2}}{K_{2}{ }_{\mathrm{Rad}}} \times 100
$$

where the Rad and Mod subscripts indicate the radioactive and modified techniques, respectively, were computed, and the results are presented in table 10 .

\section{DISCUSSION OF RESULTS}

\section{Black Earth Creek}

The measured reaeration coefficients presented in table 9 and the percentage differences presented in table 10 show that there is good agreement among the coefficients measured by the two techniques for reach 2-3. For reach 3-4, the percentage differences are larger and all are positive, indicating that the modified technique coefficients were all larger than the radioactive technique coefficient. One factor that could explain this was the wind effect. The wind blew very strongly most of the day of the Black Earth Creek experiment with speeds ranging from about 8 to $11 \mathrm{~m} / \mathrm{s}$. Measurements by the National Weather Service in Madison, Wis. indicated that the average windspeed was about $1 \mathrm{~m} / \mathrm{s}$ greater near the end of the modified technique experiment. Intermittent wind meter data collected during the experiments at the sampling cross sections indicated that windspeeds may have been about $3 \mathrm{~m} / \mathrm{s}$ greater during the modified technique experiment. Also, the direction had shifted slightly so that it was blowing more directly upstream during the time the modified technique tracers were moving through reach 3-4. The radioactive tracer experiment had ended about 3.5 hours earlier in the day. The effect of wind on the reaeration coefficient has not been quantified for natural streams, although Eloubaidy and Plate (1972) showed in a laboratory wind-water flume that reaeration coefficients were increased from 55 to 175 percent in going from no-wind conditions to windspeeds of from 6.7 to $12 \mathrm{~m} / \mathrm{s}$. Others, for example, Padden and Gloyna (1971), Zogorski and Faust (1973), and Grant (1978) concluded that wind has significant effects on the reaeration coefficient.

In evaluating the percentage differences of the results, the reproducibility of the tracer techniques must be considered. Tsivoglou (1967) did two or three repetitions on each of 14 reaches of the Jackson River. The average deviation from the mean for nine reaches was less than +10 percent, less than +6 percent for six reaches, and the maximum deviation for any reach was $\mp 18.2$ percent. Because there were generally two days between experiments on a reach, some of this variation could have been the result of actual changes in the hydraulic conditions with 


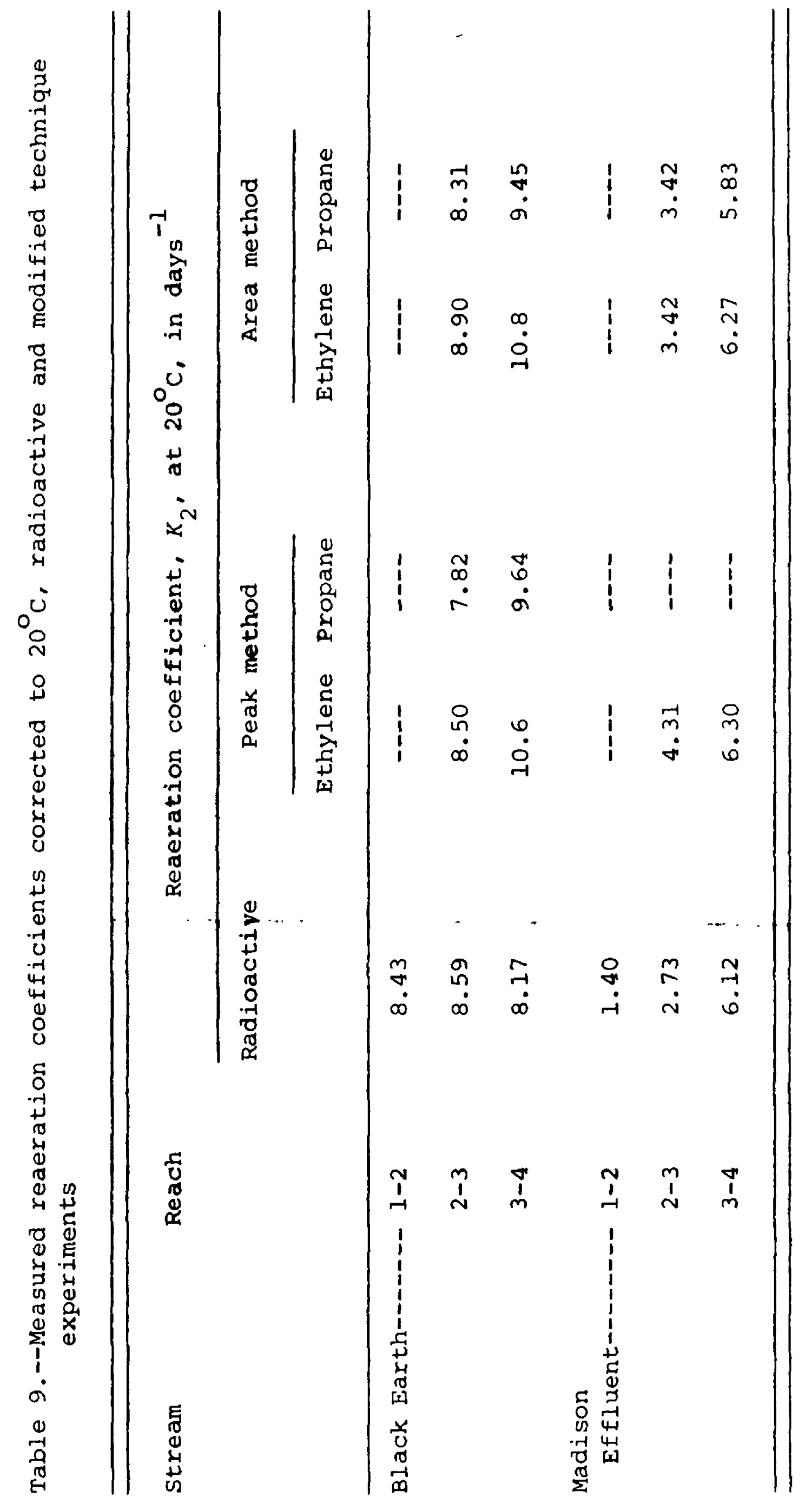




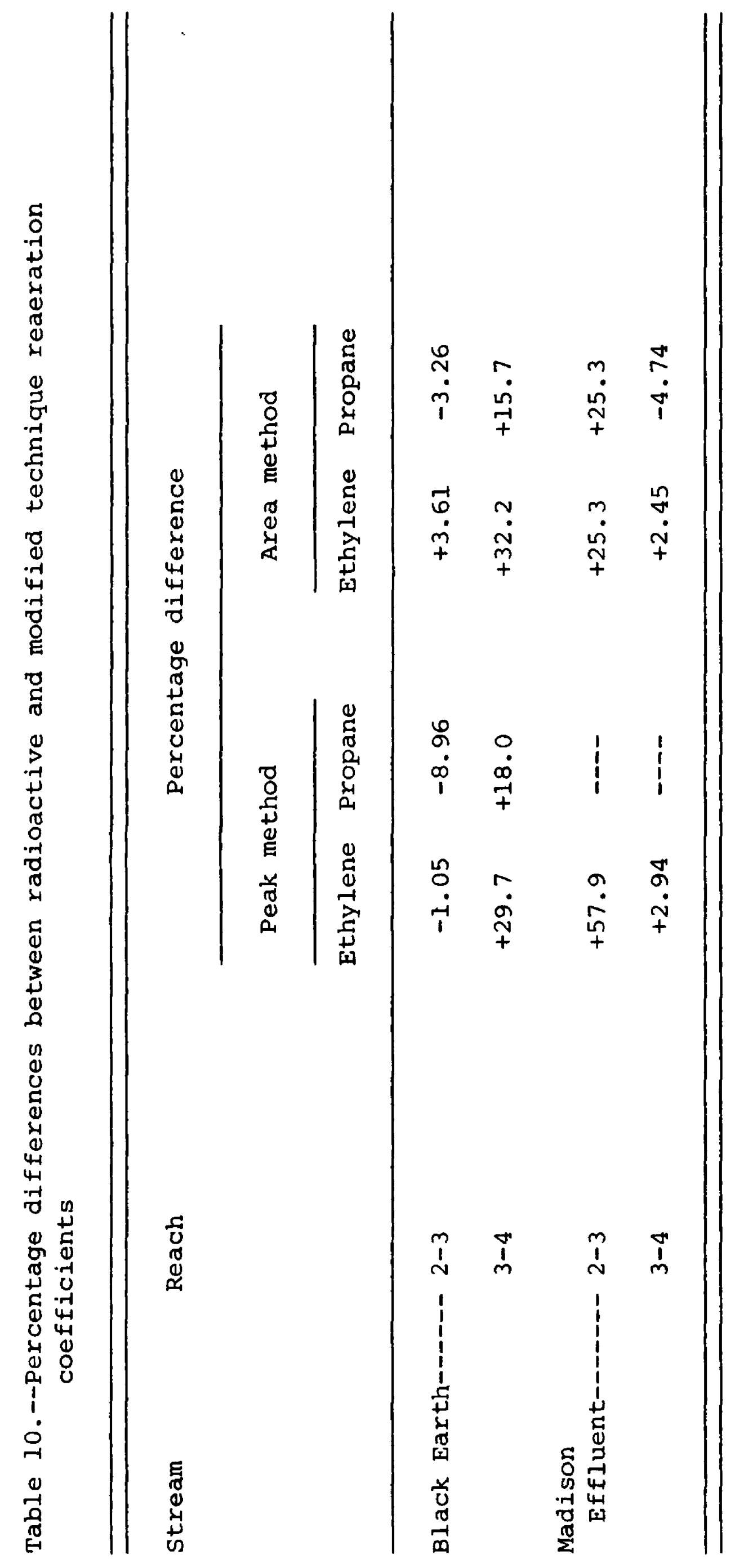


resultant changes in the reaeration coefficients. The reproducibility of the modified technique has not been established. However, consideration of reaeration coefficients presented in table 9 shows that average deviations from the mean for the four coefficients for reaches $2-3$ and 3-4 of Black Earth Creek were +3.8 and +5.7 percent, respectively. Similarly for the Madison Effluent Channel, the average deviations from the mean for the three coefficients for reaches $2-3$ and $3-4$ were \pm 11 and +3.3 percent, respectively. Because of the difficulty of reproducing hydraulic conditions in natural streams, these deviations would probably be larger for repetitive measurements on the same stream reach.

Based on these considerations of the reproducibility of the two techniques and the definite possibility of different wind effects on reach 3-4, it was concluded that the radioactive and modified tracer techniques gave comparable reaeration coefficients for the two reaches of Black Earth Creek.

\section{Madison Effluent Channel}

Evaluation of the results of the Madison Effluent Channel experiments must consider the fact that the unsteady state flow conditions necessitated estimating the dye correction factors and the water discharges. The measured reaeration coefficients presented in table 9 and the percentage differences presented in table 10 show that the differences are relatively large for reach $2-3$ and small for reach $3-4$. It is believed that unsteady flow conditions would probably produce larger reaeration coefficients than steady flow conditions because of the inherently better mixing conditions of unsteady flow. Also it is expected that the effects of the unsteady flow would be greater for reach 2-3 than for reach 3-4 for at least two reasons. First, the effect of the discharge increase would dissipate with distance downstream from the end of the underground aqueduct, and second the presence of the cascade aerator in reach 3-4 would tend to dampen the effects of the unsteady flow. The observed percentage differences support these suggestions.

Windspeed data collected on the day of the comparison study showed speeds of from about 5 to $6 \mathrm{~m} / \mathrm{s}$ throughout most of both tracer study periods. The windspeed began decreasing slowly after the radioactive tracer study concluded; however, the wind was blowing mostly across the stream channel which is deeply entrenched. Consequently, variations in windspeeds and the resultant effect on the measured reaeration coefficients in the Madison Effluent Channel comparison experiment were probably minimal.

The dye correction factors and water discharges used in the calculation of the reaeration coefficients were believed to be the best estimates possible from the available information. It is of interest, however, to calculate reaeration coefficients and percentage differences for limiting values of these parameters. There are two limiting cases, one of no dye loss and one of no increase in discharge. Both of these are extreme situations because it is known that dye loss occurs and that the discharge increased during the modified tracer experiment. 
The case of no dye loss together with equation 6 and the measured areas requires that $Q_{3}$ and $Q_{4}$ be 1.74 and $2.18 \mathrm{~m}^{3} / \mathrm{s}$, respectively. The case of no increase in discharge requires that $J_{3}$ and $J_{4}$ be 1.225 and 1.536, respectively. Using these values, the reaeration coefficients were recalculated for reaches $2-3$ and $3-4$, the coefficients were adjusted to $20^{\circ} \mathrm{C}$, and percentage differences were computed as before. Results are presented in table 11.

The only large percentage differences for these extreme cases are for the condition of no discharge increase for reach 2-3. The other percentage differences are generally small, relative to the possible experimental errors in the tracer techniques. This suggests, with the one exception, that any errors involved in the assumptions necessary for the estimation of the dye correction factors and the discharges would not greatly affect the percentage differences.

Thus, it is concluded that the percentage differences for reach $2-3$ are larger than would be expected on the basis of the probable errors in the tracer techniques. This probably was the result of the unsteady flow conditions whose effect would be greatest in reach $2-3$. The percentage differences for reach 3-4 are small, suggesting that the modified technique works well in water of the quality of that in the Madison Effluent Channel. On the other hand, a considerable part of the reaeration in reach 3-4 probably occurred at the cascade aerator which would tend to mask the effect of most of the reach. This suggests the need of additional comparison studies under steady flow conditions in streams with water of poor quality.

\section{Comparison with Predictive Equations}

The alternative to measuring the reaeration coefficient with one of the tracer techniques is to calculate the coefficient with one of the many predictive equations available in the literature. Evaluation of these predictive equations was not the purpose of the present study. However, reaeration coefficients were calculated with these equations so as to provide an indication of the range of predicted coefficients that can be expected.

The 19 predictive equations evaluated by Rathbun (1977) were used to calculate the reaeration coefficients for each of the reaches of Black Earth Creek and the Madison Effluent Channel. Basic hydraulic data necessary for the use of these equations included the average flow velocity, the average depth of flow, and the slope of the energy gradient. The average flow velocities were determined from the reach lengths and the dye time-of-travel measurements completed during the tracer experiments. Reach lengths were measured as described by Grant (1976). As discussed previously, the time-of-travel values from the radioactive and modified technique experiments were almost identical for Black Earth Creek (table 7) whereas the radioactive technique values were larger than the modified technique values for the Madison Effluent Channel (table 6). Average velocities determined from the radioactive technique time-of-travel 


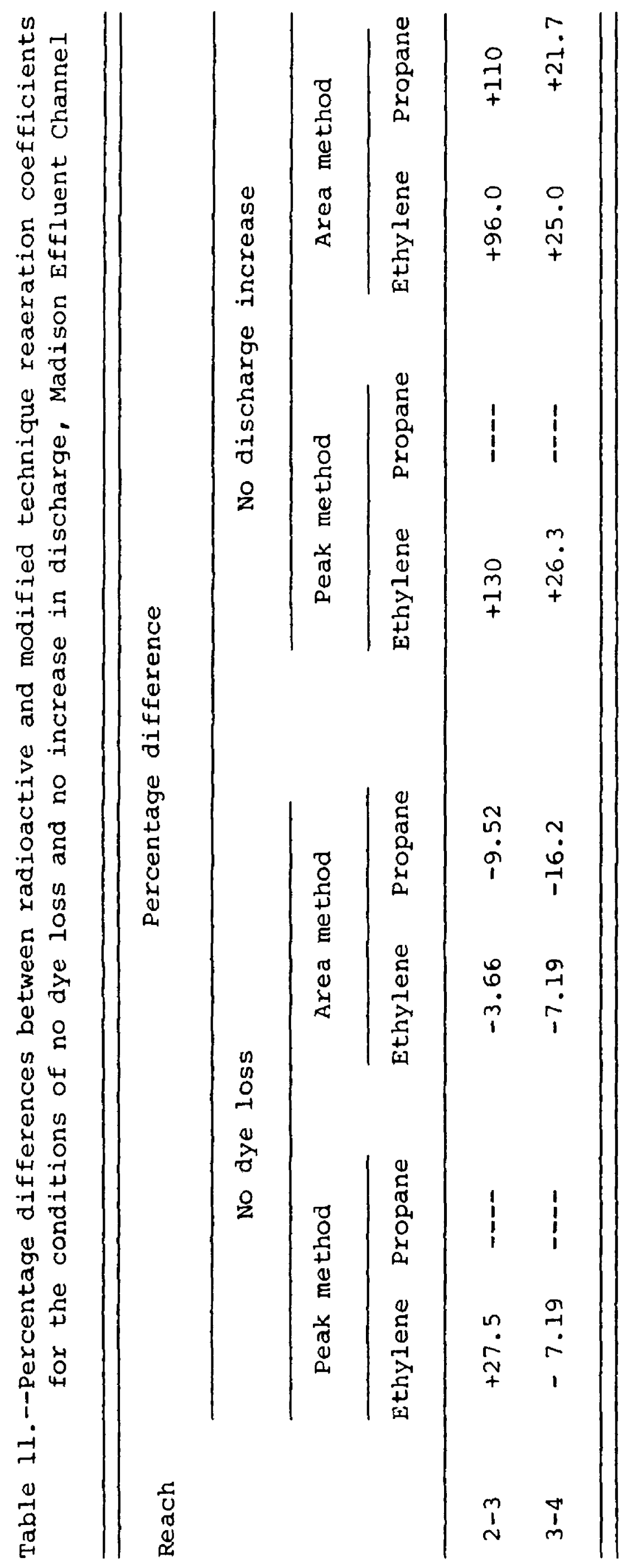


values were used in the predictive equations. The depth of flow was estimated from the cross-section measurements determined during the discharge measurements at cross-sections 2 and 4 . This is not a sufficient number of cross sections to determine a true average depth of flow. However, sections chosen for discharge measurements are usually uniform sections, and thus approximately representative of average conditions. It was assumed that equilibrium flow conditions existed and therefore, that the slope of the energy gradient was equal to the slope of the stream channel. The slopes of the channels were determined as described by Grant (1976).

The minimum and maximum predicted reaeration coefficients for each reach together with the experimental coefficients measured with the radioactive and modified tracer techniques and adjusted to $20^{\circ} \mathrm{C}$ are presented in table 12. The coefficients presented for the modified technique are averages of the peak method and area method values given in table 9. Also presented in table 12 are the number of predicted values either less than or greater than the radioactive technique coefficients.

Consideration of the results presented in table 12 shows the large range of predicted reaeration coefficients that are obtained with the predictive equations for a specific set of hydraulic conditions. These coefficient ranges varied from about 6 fold for reach 2-3 of the Madison Effluent Channel to almost 11 fold for reach 3-4 of Black Earth Creek. Therefore, it is apparent that the errors involved in using the predictive equations could be much larger than the errors involved in measuring the reaeration coefficient with one of the tracer techniques. There is, however, considerably more effort involved in measuring a reaeration coefficient than in predicting it.

Consideration of the number of predicted coefficients less than and the number greater than the radioactive technique coefficient shows for reaches 1-2 and 2-3 of the Madison Effluent Channel that, with one exception, the predicted coefficients are greater than the experimental coefficient. This could be the result of the large concentration of detergent present in the channel (fig. 6) which is known to reduce the reaeration coefficient. This observation is consistent with the previous suggestion (Rathbun, 1977) that these predictive equations overpredict reaeration coefficients relative to measured coefficients for streams receiving sewage-treatment plant effluents. On the other hand, the predictive equations generally are not applicable to artificiallyinduced reaeration such as that contributed by the cascade aerator in reach 3-4. This probably explains why about 63 percent of the equations underpredicted the coefficient for this reach. Also, the effect of the aerator is evident in that the measured coefficient for reach $3-4$ is about 2.2 times the coefficient for reach 2-3.

On Black Earth Creek, about 75 percent of the predicted coefficients for reach 1-2 and about 63 percent for reaches 2-3 and 3-4 were larger than the experimental coefficients. Again, there is the tendency for 


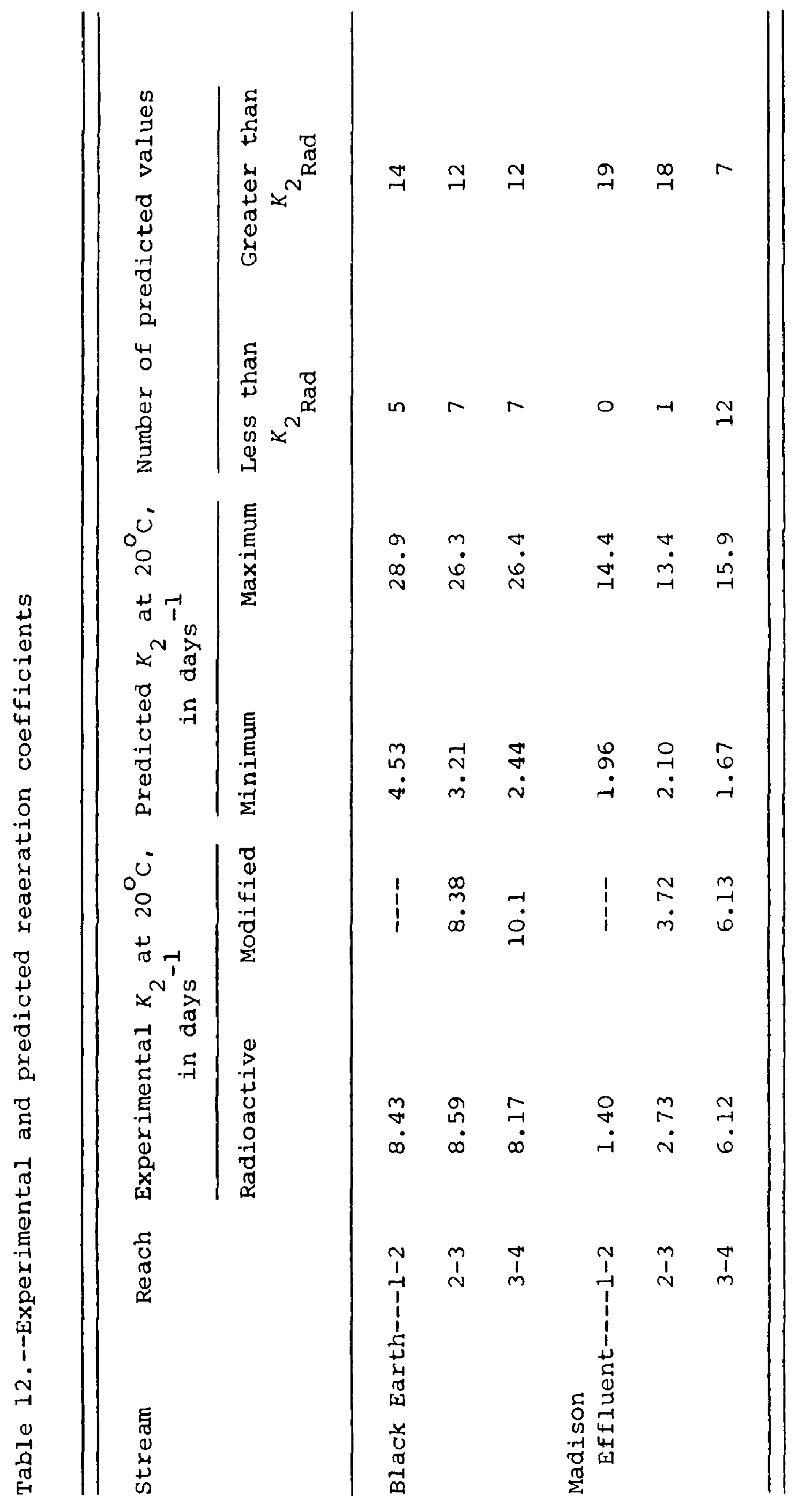


the predicted coefficients to be larger than the experimental coefficients, and this could be the result of detergents in the effluent from the wastewater treatment plant just upstream of the study reach.

\section{EVALUATION OF THE RADIOACTIVE AND MODIFIED TRACER TECHNIQUES}

Each of the two tracer techniques for measuring reaeration coefficients compared in this study has advantages and each has disadvantages. The radioactive technique uses as a tracer the noble gas, krypton, which is chemically inert. However, to obtain the necessary analytical sensitivity, a radioactive isotope of krypton has to be used. The radioactive technique uses tritium as the dispersion-dilution tracer, and the technique assumes that the tritium is conservative, that is, subject to no losses within the stream. Use of these two radioactive tracers in natural streams in many states requires a license from the U.S. Nuclear Regulatory Commission. Such licenses usually are for specific streams, thus, the measurement of other streams will require an amendment to the license. The radioactive tracers are relatively expensive and the krypton-tritium doses currently can be obtained at only a few locations in the United States.

The modified technique uses ethylene and (or) propane as tracer gases and the necessary analytical sensitivity is obtained with a stripping line-cold trap apparatus and a gas chromatograph. The tracer gases have the advantage that they are readily available and inexpensive. They have the disadvantage that they are hydrocarbons and therefore subject to possible biological degradation. However, ethylene and propane are volatile gases and would not normally be present in streams. Thus, bacteria with the ability to degrade these gases would probably not be present in large numbers. This has been discussed more fully by Rathbun, Shultz, and Stephens (1975). The tracer gases may also be subject to losses as a result of adsorption on vegetation and debris in the stream, and it is expected that the hydrocarbon gases would be more susceptible to this type of loss than krypton. Results of the comparison experiment in the Madison Effluent Channel were only approximately comparable, for reasons discussed previously. However, the fact that these gases could be used in this stream, where the flow was entirely secondary effluent and there were fairly heavy growths of aquatic weeds, with no apparent significant degradation or sorption loss, gives support to the use of these hydrocarbons as tracer gases.

The radioactive technique has the advantage that an instantaneous point source of the tracers is possible. Because the injection of the gas and dispersion-dilution tracers is at precisely the same point and same time, it is possible to sample the tracer mass a short distance below the injection point, which was designated as cross-section 1 in this study. Thus, a reaeration coefficient can be determined for the reach between cross-sections 1 and 2 . In the modified technique, the reach between cross-sections 1 and 2 serves as a mixing zone, and the first samples are collected at cross-section 2. However, should the reach between cross-sections 1 and 2 be a critical reach for which a reaeration coefficient is necessary, then the injection point can simply be moved upstream about 1 hour time of travel, making the former mixing zone the first measurement reach. 
The modified technique requires a continuous injection of the tracers because of the limited solubility of the tracer gases in water. An instantaneous injection would require a volume of water physically too large to be practical. However, the continuous injection for a short time period has proved to be a satisfactory procedure. It requires more equipment than the instantaneous injection of the radioactive technique, and it requires the attention of one individual to monitor the flow rates during the injection period.

With the assumption that tritium is conservative, the radioactive technique requires only enough samples at each cross section to define the peak concentrations. Additional hydraulic data such as discharge measurements are not necessary for the calculation of the reaeration coefficient, although such data would be desirable for characterizing the flow conditions of the stream. The radioactive technique gives one measured reaeration coefficient for each reach.

Because the rhodamine-WT dye is not completely conservative, the modified technique requires samples to define the complete dye concentrationversus-time curve at each cross section and a discharge measurement at each cross section. Observations of the water stage should be made before the arrival of the tracers and during the time the tracers are passing through the cross section. If significant changes occur, then a second discharge measurement should be made so that the discharge at the time the tracers are passing through the cross section can be accurately determined. Sampling the complete curve may require an additional field crew, depending on the separation of the measurement cross sections. However, sampling the complete dye curve permits the sampling of the complete gas curves and the determination of the reaeration coefficient by the area method. Use of the two tracer gases and both the peak and area methods gives four measured reaeration coefficients for each reach.

The peak method is probably somewhat more accurate than the area method because the peak concentrations are the largest and thus the most accurately determined. The area method requires the measurement of the much smaller concentrations on the leading and trailing edges of the tracer distributions, however, these contribute a relatively small percentage to the total area. A larger number of samples must be analyzed to define the complete curves, and thus the results should be more reliable in a statistical sense. Also the area method tends to integrate better the hydraulic conditions that determine the reaeration coefficient. on the other hand, economic considerations may preclude analyzing the large number of samples necessary to define the complete curves. The area method is independent of the dye measurements but requires waterdischarge measurements at each cross section. The peak method is dependent on the dye measurements and also requires discharge measurements as a part of the dye loss correction procedure.

The samples from a radioactive technique experiment are analyzed in a dual-channel liquid scintillation counter in which the krypton and tritium activities are determined simultaneously. Once the samples have 
been transferred to the scintillation vials, the counting process is completely automated. The samples from a modified technique experiment are analyzed in a stripping line-cold trap apparatus and a gas chromatograph, and each sample must be introduced manually into the stripping chamber. Hence, the time required to analyze the samples from a modified, technique experiment is considerably longer than the time required for the samples. of a radioactive technique experiment. The liquid scintillation equipment is of the order of twice as expensive as the gas chromatography equipment.

To summarize, the development of the radioactive tracer technique was a significant contribution to the measurement of stream reaeration coefficients, and the modified technique is a promising alternative to the use of radioactive tracers. Each technique has advantages, and each has disadvantages. The main advantage of the radioactive technique is that the tracer gas is chemically inert, the main disadvantage is that radioactive tracers are necessary. The main advantage of the modified technique is that radioactive tracers are not necessary; the main disadvantage is that the hydrocarbon tracer gases may possibly be subject to biological degradation or sorption loss during the time the gases are in the stream. However, results of the present study suggest that errors from this source are probably small and that coefficients measured with the modified technique are far more accurate than coefficients predicted with the predictive equations.

\section{SUMMARY AND CONCLUSIONS}

The radioactive and modified tracer techniques for measuring reaeration coefficients of streams were compared in two experiments on Black Earth Creek and the Madison Effluent Channel near Madison, Wis. Measured reaeration coefficients were in good agreement on the first reach of Black Earth Creek, and the modified technique coefficients were somewhat larger on the second reach. This difference was attributed to increased wind conditions during the latter stages of the modified technique experiment. Evaluation of results from the Madison Effluent Channel experiment was complicated by an unsteady flow condition which required estimation of the dye correction factors and the water discharges. The modified technique coefficients were larger than the radioactive technique coefficients for the first reach. This difference was attributed to the effect of the unsteady flow conditions. The measured coefficients for the second reach were in good agreement.

Reaeration coefficients for the four stream reaches were predicted. with 19 equations from the literature. The range of predicted coefficients was large, varying from a 6-fold range for the first reach of the Madison Effluent Channel to an almost 11-fold range for the second reach of Black Earth Creek. It was concluded that reaeration coefficients measured with either the radioactive or modified tracer techniques are far more accurate than coefficients predicted with the predictive equations.

The results of the two comparison tests suggest that the modified technique is a promising procedure that does not require radioactive 
tracers for the measurement of stream reaeration coefficients. The use of the hydrocarbon tracer gases in a stream such as the Madison Effluent Channel with no apparent significant degradation of the gases or sorption loss is encouraging. However, evaluation of the results of the Madison Effluent Channel experiment was complicated by the unsteady flow condition, and assumptions were necessary. Therefore, additional comparison studies under steady flow conditions in streams with water of poor quality are desirable.

\section{REFERENCES CITED}

Bennett, J. P., and Rathbun, R. E., 1972, Reaeration in open channel flow: U.S. Geol. Survey Prof. Paper 737, 75 p.

Buchanan, T. J., and Somers, W. P., 1969, Discharge measurements at gaging stations: U.S. Geol. Survey Techniques Water-Resources Inv., book 3 , chap. A8, $65 \mathrm{p}$.

Elmore, H. L., and West, W. F., 1961, Effect of water temperature on stream reaeration: Am. Soc. Civil Engineers Proc., Jour. Sanitary Eng. Div., v. 87, no. SA-6, p. 59-71.

Eloubaidy, A. F., and Plate, E. J., 1972, Wind shear-turbulence and reaeration coefficient: Am. Soc. Civil Engineers Proc., Jour. Hydraulics Div., v. 98, no. HY-1, P. 153-170.

Grant, R. S., 1976, Reaeration-coefficient measurements of 10 small streams in wisconsin using radioactive tracers. . . with a section on the energydissipation model: U.S. Geol. Survey Water-Resources Inv. 76-96, 50 p.

1978, Reaeration capacity of the Rock River between Lake Koshkonong, Wisconsin, and Rockton, Illinois: U.S. Geol. Survey Water-Resources Inv. $77-128,38 \mathrm{p}$.

McAuliffe, C., 1966, Solubility in water of paraffin, cycloparaffin, olefin, acetylene, cycloolefin, and aromatic hydrocarbons: Jour. Phys. Chemistry, v. 70 , no. 4, p. 1267-1275.

Padden, T. J., and Gloyna, E. F., 1971, Simulation of stream processes in a model river: Rept. no. EHE-70-23, CRWR-72, Austin, Univ. Texas, 130 p.

Rathbun, R. E., 1977, Reaeration coefficients of streams---state-of-the-art: Am. Soc. Civil Engineers Proc., Jour. Hydraulics Div., v. 103, no. HY-4, p. $409-424$.

Rathbun, R. E., Shultz, D. J., and Stephens, D. W., 1975, Preliminary experiments with a modified tracer technique for measuring stream reaeration coefficients: U.S. Geol. Survey Open-File Rept. 75-256, 36 p. 
Rathbun, R. E., Stephens, D. W., Shultz, D. J., and Tai, D. Y., 1978, Laboratory studies of gas tracers for reaeration: Am. Soc. Civil

Engineers Proc., Jour. Envir. Eng. Div., v. 104, no. EE2, p. 215-229.

Shultz, D. J., Pankow, J. F., Tai, D. Y., Stephens, D. W., and Rathbun, R. E., 1976, Determination, storage, and preservation of low molecular weight hydrocarbon gases in aqueous solution: U.S. Geol. Survey Jour. Research, v. 4, no. 2, p. 247-25l.

Tsivoglou, E. C., 1967, Tracer measurement of stream reaeration: Federal Water Pollution Control Adm. Rept., $86 \mathrm{p}$.

1974, The reaeration capacity of Canandaigua outlet, Canandaigua to Clifton Springs: New York State Dept. Environmental Conservation, Proj. no. C-5402, 79 p.

Tsivoglou, E. C., O'Connell, R. L., Walter, C. M., Godsil, P. J., and Logsdon, G. S., 1965, Laboratory studies, part I of tracer measurements of atmospheric reaeration: Water Pollution Control Federation Jour., v. 37 , no. 10, p. 1343-1362.

Tsivoglou, E. C., Cohen, J. B., Shearer, S. D., and Godsil, P. J., 1968, Field Studies, part II of tracer measurement of stream reaeration: water Pollution Control Federation Jour., v. 40, no. 2, pt. 1, p. 285-305.

Tsivoglou, E. C., and Wallace, J. R., 1970, Hydraulic properties related to stream reaeration, in Isotope Hydrology 1970: Internat. Atomic Energy Agency, Vienna, p. 509-522.

1972, Characterization of stream reaeration capacity: U.S. Environmental Protection Agency Ecological Research Ser. Rept. EPA-R3-72-012, 317 p.

Tsivoglou, E. C., McClanahan, M. A., and Sanders, W. M., 1972, symposium on direct tracer measurement of the reaeration capacity of streams and estuaries, 7-8 July 1970: available from U.S. Dept. Commerce, Natl. Tech. Inf. Service, Springfield, VA 22151 as report $\mathrm{PB}-218478,98 \mathrm{p}$.

Wilson, J. F., Jr., 1968, Fluorometric procedures for dye tracing: U.S. Geol. Survey Techniques Water-Resources Inv., book 3, chap. Al2, 31 p.

Yotsukura, N., Fischer, H. B., and Sayre, W. W., 1970, Measurement of mixing characteristics of the Missouri River between Sioux City, Iowa, and Plattsmouth, Nebraska: U.S. Geol. Survey Water-Supply Paper 1899-G, 29 p.

Zogorski, J. S., and Faust, S. D., 1973, Critical review of methods available to measure and to calculate the atmospheric reaeration rate constant, Part I of Atmospheric reaeration capacity of streams: Environmental Letters, v. 4, no. 1 , p. 35-59. 